\title{
Tabelas de vida multirregional e caracterização dos fluxos populacionais entre cidades de pequeno, médio e grande porte - Brasil, 1986-1991
}

\author{
Maria Helena Constantino Spyrides \\ Universidade Federal do Rio Grande do Norte (UFRN) \\ spyrides@ccet.ufrn.br \\ Ernesto F. L. Amaral \\ Universidade do Texas em Austin \\ eflamaral@gmail.com
}

\section{Resumo}

O processo de desconcentração industrial dos últimos 20 anos está ocasionando o crescimento populacional de regiões que não recebiam um considerável fluxo imigratório. Uma questão que se levanta é de que modo está ocorrendo tal fluxo dos grandes municípios brasileiros para cidades menores. Torna-se necessária uma análise desse fluxo migratório, que possibilite testar a hipótese de que está ocorrendo uma reversão do fluxo migratório em direção às grandes metrópoles. Em primeiro lugar, é realizada uma caracterização sócio-econômica desses migrantes, a partir de dados censitários, possibilitando conhecer o perfil desses indivíduos, os quais são agrupados em fluxos entre cidades de diferentes portes. Posteriormente, são utilizadas tabelas de vida multirregional que possibilitam perceber qual o tempo médio vivido por um indivíduo em municípios de porte pequeno, médio e grande, levando em consideração seu local de residência em 01 de setembro de 1986 e 1991, através de dados do Censo Demográfico de 1991. Com os dados descritivos, constatou-se que o fluxo de pequenos municípios para os de maior porte é caracterizado por indivíduos que apresentam maiores níveis sócio-econômicos do que aqueles que se direcionam de grandes para pequenos municípios. Com os dados das tabelas de vida, constatou-se que há uma maior tendência de pessoas de cidades grandes migrarem para outros municípios de diferentes portes. Deste modo, o que se está afirmando é que as grandes cidades possuem ou atraem pessoas com melhores condições de vida, porém os habitantes com origem nestas cidades são as que mais tendem a apresentar um maior número de anos vividos em municípios de outros portes. Isto pode estar evidenciando uma mudança no padrão migratório do Brasil, que antes era caracterizado por um fluxo predominantemente de pequenos para médios ou grandes municípios, e agora está apresentando uma maior tendência no fluxo de maiores para menores cidades.

\section{Palavras-chave}

Migração. Tabela de vida multirregional. Cidades. Brasil. Chernoff Face.

\section{Citação}

Spyrides MHC, Amaral EFL. 2002. "Tabelas de vida multirregional e caracterização dos fluxos populacionais entre cidades de pequeno, médio e grande porte - Brasil, 1986-1991." Open Science

Framework Preprints, November 4. (https://doi.org/10.31219/osf.io/9bjps) 


\section{Introdução}

Após 1930, no período marcado pelo fim do apogeu da economia cafeeira, o Brasil experimentou um processo de crescente urbanização que se estendeu até os anos 80. Durante o período de 1940-70 houve um aumento na participação das cidades de maior tamanho na população do país. As migrações rural-urbanas começaram a se intensificar contribuindo para a concentração progressiva e acentuada da população em cidades cada vez maiores. A mecanização do campo, incentivada por subsídios do governo, levou a uma redução da necessidade de mão-de-obra nesse setor, acarretando o maciço êxodo rural nas décadas de 60 e 70 . Além disso, o país vivenciava um crescimento vegetativo acelerado, com altas taxas de fecundidade (SACHS, 1999).

A urbanização prosseguiu num ritmo acelerado até a década de 1970, quando se observou o início de quebra da tendência de concentração (MARTINE, 1994). Nos anos 80 houve uma alteração profunda no padrão de urbanização do país, com uma significativa redução no ritmo de crescimento das grandes cidades. Segundo BAENINGER (1998), a taxa de crescimento populacional metropolitana nacional apresentou uma redução considerável. Houve um arrefecimento da migração rural-urbana e inter-regional, assim como uma mudança do padrão demográfico, com significativa redução das taxas de fecundidade.

A redução de demanda por trabalho nos grandes municípios acentuou o declínio da migração para São Paulo e sua área metropolitana, alterando as trajetórias migratórias. Dessa forma, a desconcentração industrial, iniciada nesse período e aprofundada posteriormente, fez surgir um movimento populacional para várias regiões do país (DINIZ, 1995).

Segundo DINIZ (1995), esse processo de desconcentração industrial dos últimos 20 anos está ocasionando o crescimento populacional de regiões que não recebiam um considerável fluxo imigratório. Assim sendo, uma questão que se levanta atualmente é de que modo está ocorrendo tal fluxo dos grandes municípios brasileiros para cidades menores. Torna-se necessária uma análise desse fluxo migratório, que possibilite testar a hipótese de que está ocorrendo uma reversão daquele fluxo migratório em direção às grandes metrópoles. Para isto, são utilizadas as tabelas de vida multirregional que possibilitam perceber qual o tempo médio vivido por um indivíduo em municípios de porte pequeno, médio e grande, levando em consideração seu local de residência em 01 de setembro de 1986 e 1991, através de dados do Censo Demográfico de 1991. Além disso, é realizada uma caracterização sócio-econômica desses migrantes, a partir de dados censitários, possibilitando conhecer o perfil desses indivíduos, os quais são agrupados em fluxos entre cidades de diferentes portes. 


\section{Material e método}

\subsection{Levantamento dos dados}

Para cumprir os objetivos propostos neste estudo, o procedimento metodológico compreende quatro etapas de levantamento das informações necessárias. A primeira compreende a classificação dos municípios por porte, ou seja, pelo número total de habitantes do município. O critério utilizado para classificar os municípios quanto ao porte baseou-se na definição adotada pelo IBGE no censo de 1991 onde, consideraram-se cidades de "pequeno porte (1)" aquelas com menos de 100 mil habitantes, cidades de "médio porte (2)" aquelas entre 100 e 500 mil habitantes e cidades de "grande porte (3)", aquelas cidades com mais de 500 mil habitantes. Estas informações foram obtidas através de programas desenvolvidos no SAS com base no Censo de 1991. Esta classificação foi feita a partir da situação dos municípios no momento da entrevista, mantendo-se a mesma classificação para a data fixa de setembro de 1986. Desta forma, dos 4491 municípios existentes em 1991, 95,88\% foram classificados como pequeno porte; $3,56 \%$ em médio e $0,56 \%$ grande porte.

\section{FIGURA 1}

Proporção de Cidades e Proporção Populacional por classificação do porte das cidades brasileiras, 1991.

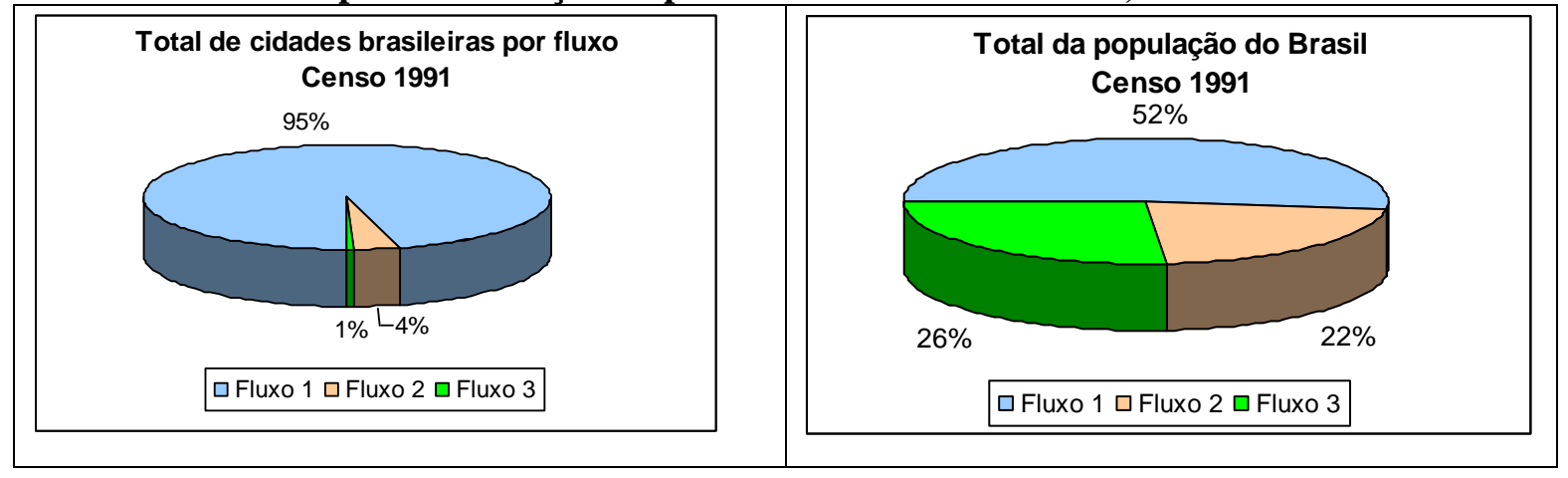

A segunda etapa de levantamento dos dados compreendeu a obtenção da distribuição populacional, segundo sexo e grupo etário, de acordo com os fluxos migratórios estabelecidos, ou seja, a mobilidade populacional referente ao porte da cidade de origem e destino. Observou-se, assim, nove tipos de fluxos: Fluxo ij - correspondendo àquelas pessoas que estavam em i na data fixa e em $\mathrm{j}$ na data da entrevista, com $\mathrm{i}=1,2,3 \mathrm{e} \mathrm{j}=1,2,3$. Neste procedimento também foram desenvolvidos alguns programas no SAS para extrair as informações do Censo de 1991, além daquelas referentes a distribuição populacional, aquelas referentes aos nascimentos, necessários para o cálculo das taxas específicas de fecundidade.

A terceira etapa consistiu na obtenção das taxas específicas de mortalidade $\left(m_{x}\right)$. O ideal seria ter calculado estas taxas com base na experiência de morte resultante da classificação das cidades 
quanto ao porte a partir dos dados do registro civil ou do Sistema de Informação de Mortalidade (SIMDATASUS) devidamente corrigidos. Porém, esta tarefa não seria tão simples, dados os problemas existentes na declaração das informações, principalmente no que se refere aos pequenos municípios. Sendo assim, optou-se em utilizar informações já disponibilizadas pelo PRONEX - CEDEPLAR, relativas às taxas específicas de mortalidade do Brasil como uma média para cada um dos grupos de municípios classificados quanto ao porte pequeno, médio e grande.

A última etapa de levantamento de informações compreendeu a coleta de informações sócioeconômicas dos nove tipos de fluxos para melhor compreender as diferenças que caracterizam tais movimentos.

\subsection{Demografia multirregional}

Com o intuito de analisar simultaneamente a dinâmica espacial envolvida no sistema de subpopulações interdependentes ligadas por este conjunto de fluxos migratórios, utilizou-se o método de demografia multirregional. Este método consiste num conjunto de técnicas que envolvem cálculos matriciais abrangendo os fluxos emigratórios de uma subpopulação para as demais envolvidas no sistema, levando-se em conta, a influência das componentes demográficas da fecundidade e mortalidade simultaneamente.

Segundo ROGERS (1995) existem duas classes de modelos comumente utilizados para examinar o crescimento e a estrutura de uma população multirregional sob regimes particulares de fecundidade, mortalidade e migração: o modelo de tabela de vida e o modelo de projeção. Este trabalho deteve-se a desenvolver o modelo de tabela de vida que permite que várias coortes se interajam durante o processo da evolução da demografia multirregional, com o intuito de obter o tempo médio de vida vivido por uma pessoa em cada um de seus movimentos.

\section{Procedimentos para a Obtenção das Esperanças de Vida}

Com base nas informações levantadas, quais sejam, distribuição populacional por sexo e grupo etário em cada fluxo analisado, nascimentos e taxas específicas de mortalidade, procedeu-se aos seguintes cálculos, utilizando o método opção 2 (ROGERS, 1995), que envolve a estimação com o uso das proporções de sobrevivência condicionais: 
a) Matriz de proporções de sobrevivência condicionais, dada por:

$$
\tilde{S}_{i j}(x-5)=\frac{K_{i j}(x)}{\sum_{k=1}^{3} K_{i k}(x)}, \quad k=1,2,3 .
$$

Onde:

$K_{i j}(x)$ representa o número de migrantes registrados pelo censo da cidade de porte i no tempo t-5 para a cidade de porte $\mathrm{j}$ no tempo $\mathrm{t}$;

$\sum_{k=1}^{m} K_{i k}(x)$ é o número de migrantes da cidade de porte i no tempo t-5 para todas as cidades de porte $\mathrm{k}$ no tempo t.

b) Matriz de probabilidades de transição condicionais, calculadas com base nas proporções de sobrevivência condicionais através da primeira interpolação linear definida por Rees \& Wilson, 1977 (citados por ROGERS, 1995):

$$
P(x)=\tilde{P}(x) P_{\sigma}(x)=\frac{1}{2}[\tilde{S}(x-5)+\tilde{S}(x)] P_{\sigma}(x),
$$

onde:

$P_{\sigma}(x)$ é uma matriz de probabilidades de sobrevivência que descondicionaliza a matriz $\widetilde{P}(x)$ de probabilidades de sobrevivência condicionais e;

$$
P_{i \sigma}(x)=\frac{1-2,5 M_{i d}(x)}{1+2,5 \sum_{k=1}^{3} \tilde{P}_{i k}(x) M_{k d}(x)},
$$

sendo $M_{i d}(x)$ a taxa de mortalidade no grupo etário de x a x +4 no porte $\mathrm{i}$.

Atenção diferenciada deve ser dada para o primeiro grupo etário. Neste caso o cálculo é feito da seguinte maneira:

$$
P(0)=\frac{1}{2}\left\{[\tilde{S}(-5)]^{2}+\tilde{S}(0)\right\} P_{\sigma}(0)
$$

para o grupo etário de 0 a 4 anos. 
c) Matriz do número esperado de sobreviventes provenientes de cidades classificadas em porte i e que estejam vivendo em cidades classificadas em porte $\mathrm{j}$ na idade $\mathrm{x}+5$, no tempo $\mathrm{t}+5$.

$$
l(x+5)=P(x) . l(x) .
$$

d) Matriz do total de anos-pessoa vivendo em cidade classificadas em j, entre as idades de $\mathrm{x}$ e $\mathrm{x}+5$ pelos indivíduos que viviam em cidades de porte i na idade de $\mathrm{x}$ anos.

$$
L_{i j}=\frac{5}{2}\left\{l_{x}+l_{x+5}\right\} \text {. }
$$

e) Matriz do total esperado de anos-pessoa a serem vividos a partir da idade $\mathbf{x}$ pela coorte $\mathrm{l}_{\mathrm{i}}(\mathbf{x})$, segundo a classificação de porte da cidade de residência.

$$
T_{i j}(x)=\sum_{x=0}^{w} L_{i j}(x) .
$$

\section{f) Esperança de Vida}

$$
e_{i j}=T_{i j}(x) \cdot\left[l_{i j}(x)\right]^{-1} \text {. }
$$

g) Como o último grupo etário (80 anos e mais) é aberto, o cálculo do ${ }_{0} \mathrm{~L}(80)$ foi diferenciado do demais. Desta forma, calculou-se inicialmente ${ }_{80} \mathrm{~L}(80)$ da seguinte maneira:

$$
{ }_{80} \hat{L}(80)=\left\{\frac{2}{5}[I+\tilde{S}(75)]^{-1}[I-\tilde{S}(75)]+M_{d}(80)\right\}^{-1},
$$

sendo $\mathrm{M}_{\mathrm{d}}(80)$ é a matriz diagonal das taxas de mortalidade e, então, procedeu-se ao cálculo de ${ }_{0} \mathrm{~L}(80)$ através do produto matricial:

$$
{ }_{0} \hat{L}(80)={ }_{80} \hat{L}(80){ }_{0} \hat{l}(80) .
$$

Obtendo-se, assim, a matriz de totais de anos-pessoa vividos pelo grupo aberto de 80 anos e mais.

h) Razão de Sobrevivência é a proporção de indivíduos da idade x a x+4 que sobreviveram até as idades de $x+5$ a $x+9$ anos no tempo $t+5$, logo é dado por:

$$
S(x)=L(x+5) \cdot L(x)^{-1} \text {. }
$$




\section{Resultados}

\subsection{Caracterização dos fluxos populacionais}

Para que se conheça melhor os movimentos migratórios, é necessário fazer um diagnóstico do perfil dos migrantes em cada um dos fluxos. Identificando a estrutura etária de cada movimento, as características sócio-econômicas destas pessoas e os indicadores demográficos, é possível delinear o perfil destes migrantes, revelando motivações distintas dos migrantes ao se mudar para uma cidade de porte distinto ao de origem.

A Figura 2a apresenta a estrutura etária dos migrantes por fluxo entre cidades e a Figura $2 b$ destaca a estrutura etária apenas daqueles que migraram para cidades de mesmo porte, excluindo os que permaneceram na mesma cidade de origem. Observa-se que para os fluxos constituídos ou por pessoas que permaneceram em suas cidades de origem ou que migraram para cidades de mesmo porte, as pirâmides mostram uma tendência a uma redução da base a medida que aumenta o porte das cidades, ou seja, nas cidades de maior porte a fecundidade é menor. Nota-se que o Fluxo 33 apresenta um padrão populacional convergindo para a estabilidade. Para quem migra das cidades de pequeno porte rumo às cidades de médio e grande porte, há uma maior concentração de pessoas em idades entre 20-24 anos, tanto homens quanto mulheres, sendo mais expressivo o fluxo para as de grande porte.

Quando se observa o movimento contrário, ou seja, da migração de cidades de porte maior para as de menor porte, constata-se que proporções de pessoas em faixas etárias mais elevadas (25 ou mais) tendem a aumentar, o que pode indicar dentre estes migrantes àqueles de retorno. 
FIGURA 2a - DISTRIBUIÇÃO ETÁRIA DOS FLUXOS ENTRE CIDADES DE DIFERENTES PORTES - BRASIL, 1991

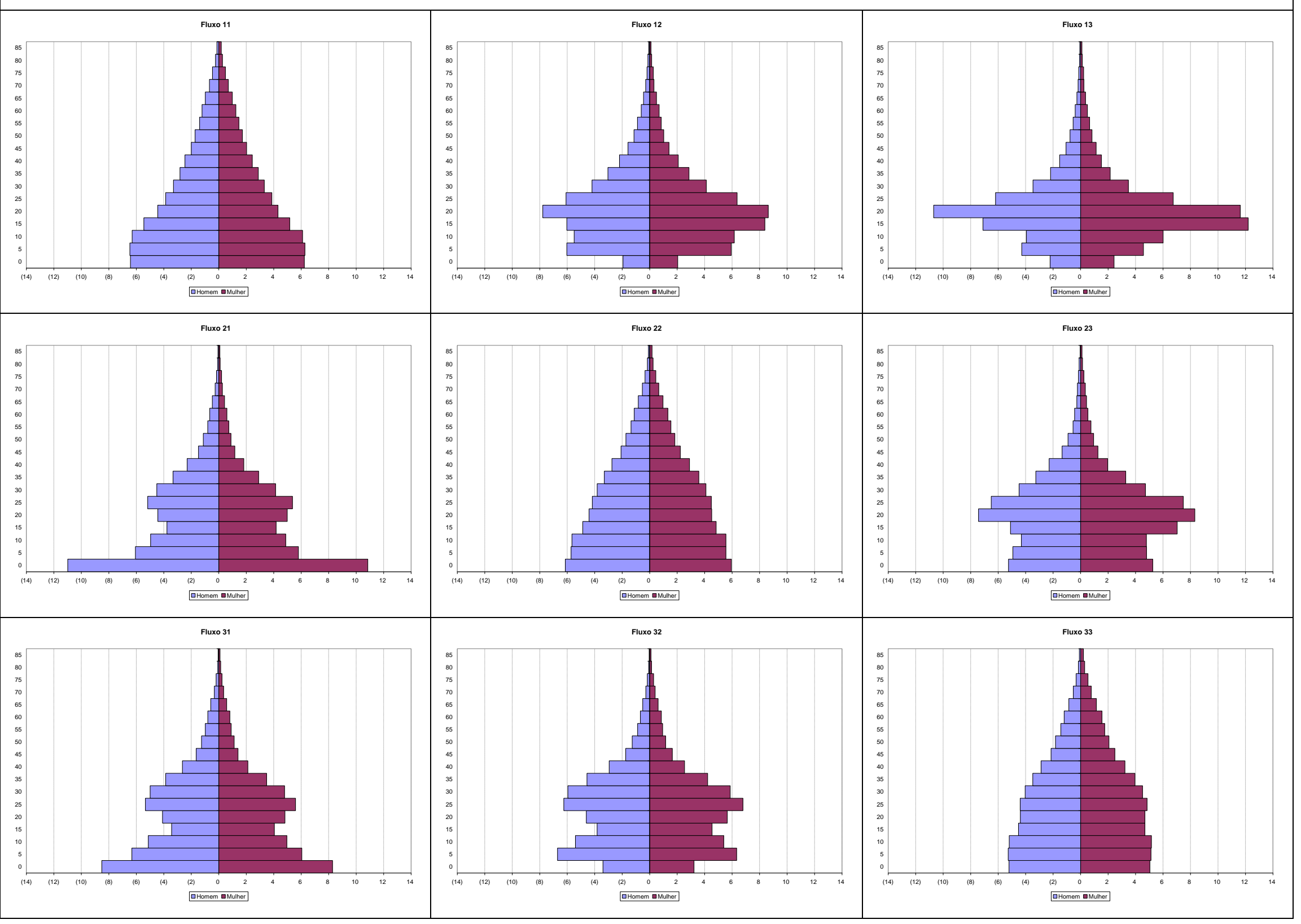




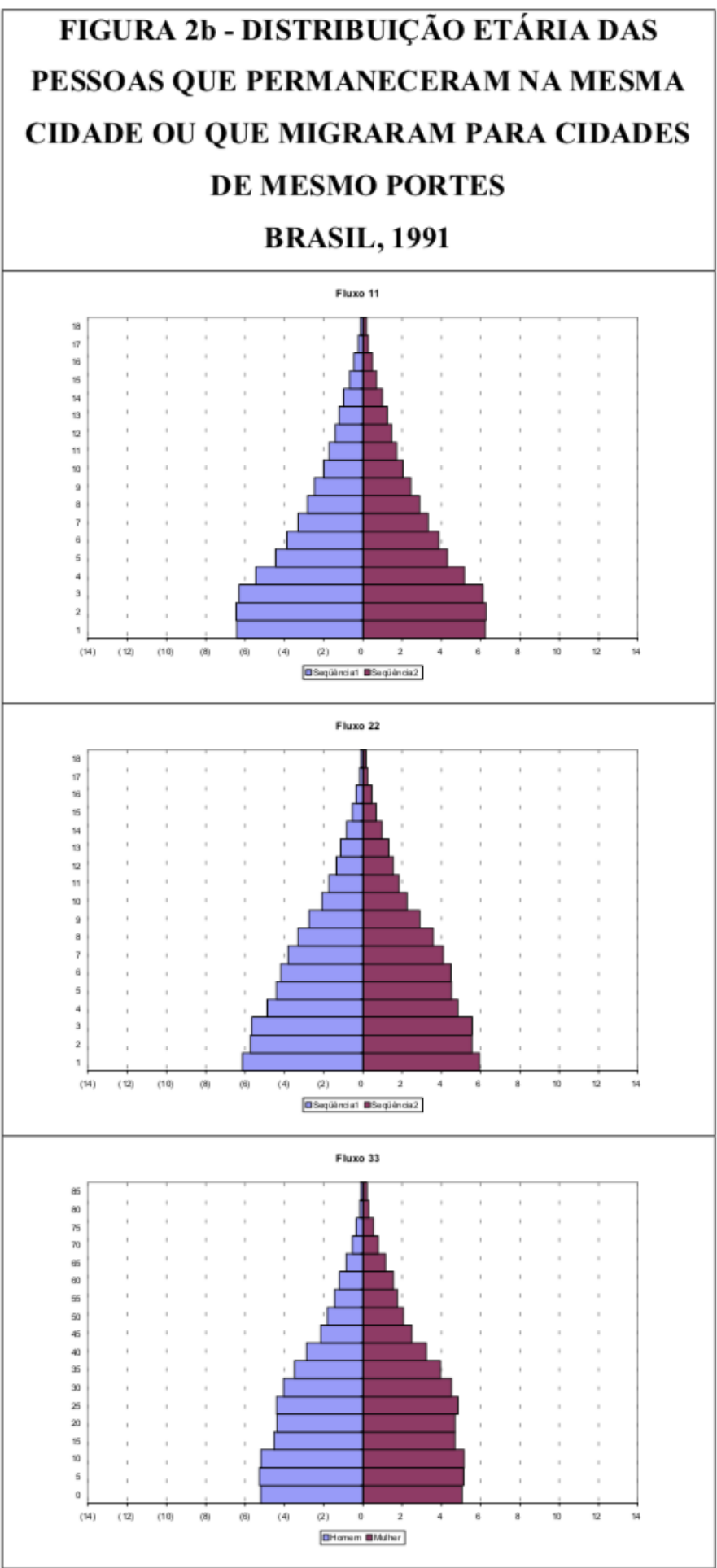


Surpreendentemente, a fecundidade das pessoas do Fluxo 21, ou seja, daquelas que migraram de uma cidade média para uma de porte pequeno, mostra-se bastante expressiva. Isto pode ser constatado pela Tabela 1, que apresenta as Taxas Específicas de Fecundidade (TEF) e as Taxas de Fecundidade Total (TFT), por movimento migratório. As TFTs das mulheres que migram para os grandes centros urbanos são menores. Para o Fluxo 11 a taxa é de 2,95 filhos por mulher, passando para 2,83 para as mulheres que migraram das cidades de porte pequeno para médio (Fluxo 12) e de 2,22 filhos por mulher para as de Fluxo 13.

\begin{tabular}{c|cccccccccc}
\multicolumn{10}{c}{ TABELA 1 } \\
\multicolumn{10}{c}{ TAXAS ESPECIFICAS DE FECUNDIDADE E TAXAS DE FECUNDIDADE TOTAL } \\
segundo fluxos entre cidades brasileiras de diferentes portes - Censo 1991 \\
Grupo & Fluxo & Fluxo & Fluxo & Fluxo & Fluxo & Fluxo & Fluxo & Fluxo & Fluxo \\
Etário & 11 & 12 & 13 & 21 & 22 & 23 & 31 & 32 & 33 \\
\hline 15 & 0,0675 & 0,0755 & 0,0524 & 0,1096 & 0,0569 & 0,0555 & 0,1045 & 0,0823 & 0,0447 \\
20 & 0,1623 & 0,1582 & 0,1179 & 0,1956 & 0,1272 & 0,1195 & 0,1898 & 0,1706 & 0,1011 \\
25 & 0,1463 & 0,1440 & 0,1218 & 0,1605 & 0,1205 & 0,1249 & 0,1532 & 0,1532 & 0,1050 \\
30 & 0,1030 & 0,1006 & 0,0777 & 0,1044 & 0,0769 & 0,0808 & 0,0965 & 0,0993 & 0,0693 \\
35 & 0,0668 & 0,0534 & 0,0447 & 0,0601 & 0,0411 & 0,0489 & 0,0509 & 0,0458 & 0,0346 \\
40 & 0,0341 & 0,0289 & 0,0212 & 0,0309 & 0,0166 & 0,0158 & 0,0204 & 0,0237 & 0,0130 \\
45 & 0,0099 & 0,0060 & 0,0087 & 0,0061 & 0,0042 & 0,0000 & 0,0056 & 0,0042 & 0,0027 \\
\hline TFT & $\mathbf{2 , 9 5}$ & $\mathbf{2 , 8 3}$ & $\mathbf{2 , 2 2}$ & $\mathbf{3 , 3 4}$ & $\mathbf{2 , 2 2}$ & $\mathbf{2 , 2 3}$ & $\mathbf{3 , 1 1}$ & $\mathbf{2 , 9 0}$ & $\mathbf{1 , 8 5}$ \\
\hline
\end{tabular}

Examinando o estado civil dos migrantes apresentado nas Figuras 3 e 4, contata-se que há uma tendência de deslocamentos de solteiros em direção aos grandes centros, enquanto que em direção às cidades menores a tendência observada é de migrantes em primeiras uniões. Este comportamento é verificado tanto entre os homens quanto entre as mulheres. Este fato é bastante compreensível dado que as pessoas que migram para os grandes centros têm a intenção, na maioria das vezes, de procurar emprego e tendem a postergar o casamento e a reprodução. 
FIGURA 3

SITUAÇÃO CONJUGAL ATUAL, SEXO MASCULINO - BRASIL, 1991

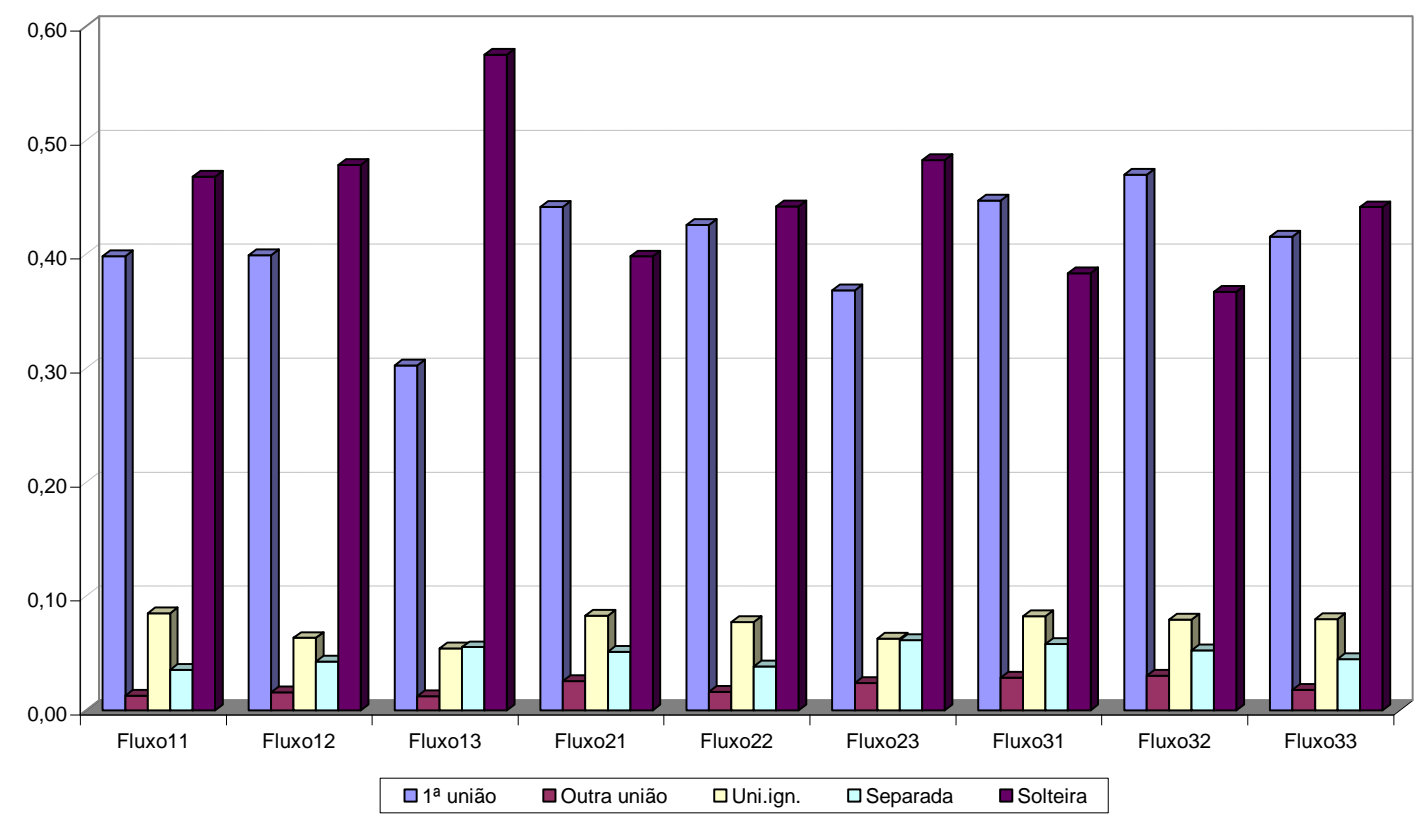

FIGURA 4

SITUAÇÃO CONJUGAL ATUAL, SEXO FEMININO - BRASIL, 1991

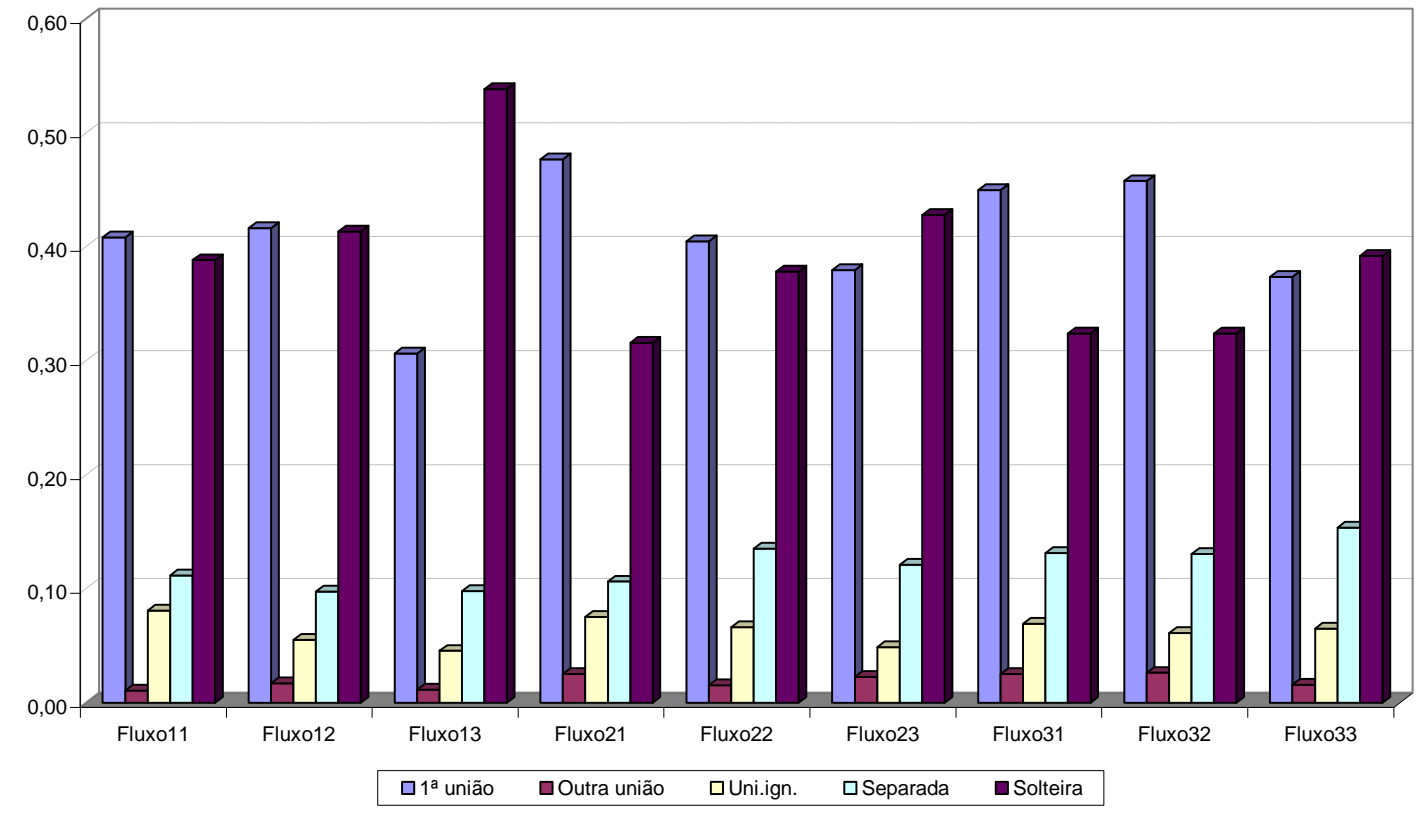


Um atrativo da migração rumo às maiores cidades é a perspectiva de trabalho formal. Isto pode ser observado pelos percentuais de homens com carteira de trabalho assinada. A Figura 5 mostra uma tendência crescente do percentual de homens com carteira assinada entre os que migraram para cidades de maior porte. Para as mulheres (Figura 6) este comportamento é mais evidente para aquelas cujas origens são as cidades de maior porte e, as de origem em cidades de pequeno porte, mesmo procurando os grandes centros, têm dificuldade de se colocarem no mercado formal de trabalho, embora o desemprego seja menor. Provavelmente, pode ser explicado pelo tipo de ocupação, geralmente na área de serviços.

FIGURA 5

POSSE DE CARTEIRA DE TRABALHO ASSINADA, SEXO MASCULINO - BRASIL, 1991

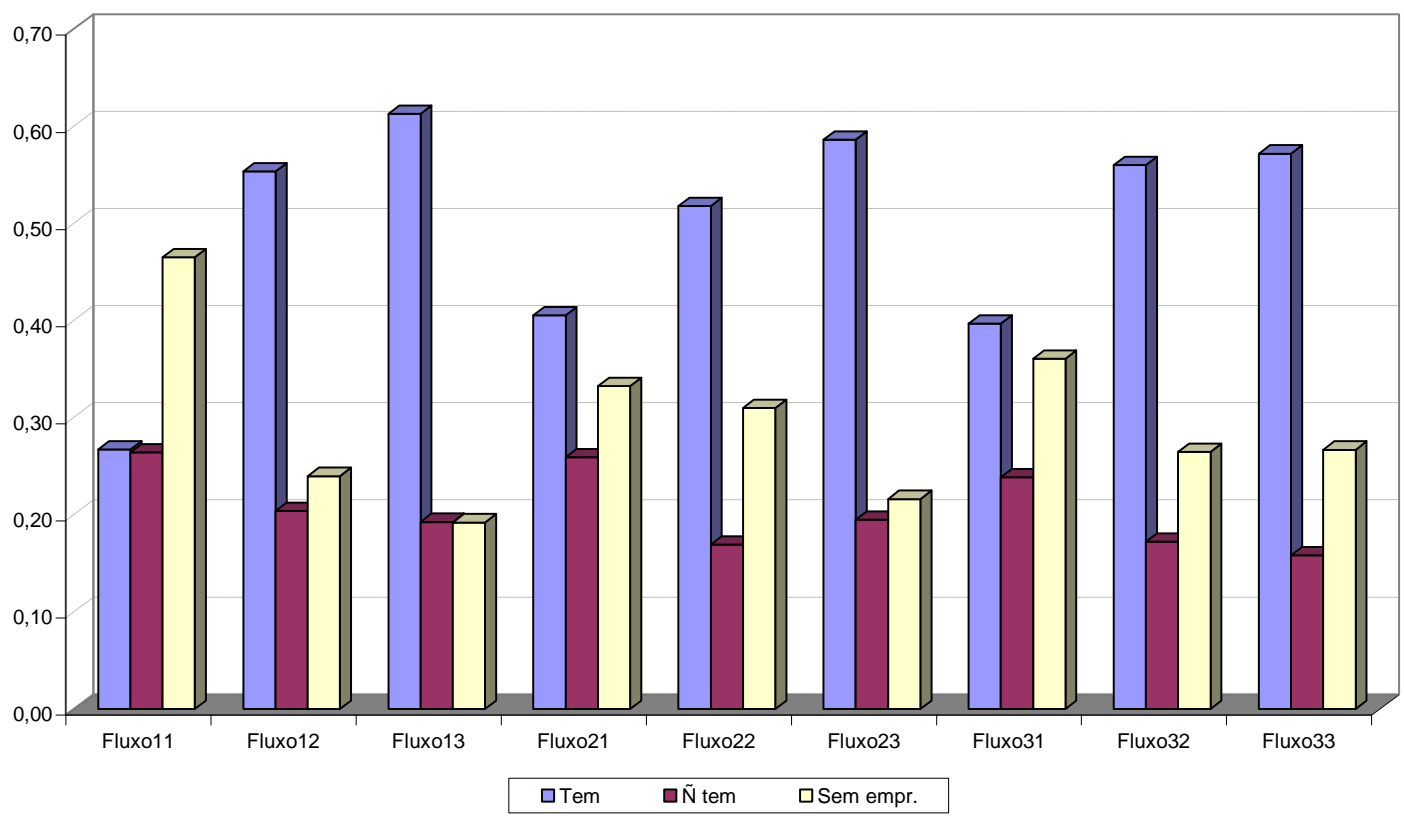


FIGURA 6

POSSE DE CARTEIRA DE TRABALHO ASSINADA, SEXO FEMININO - BRASIL, 1991

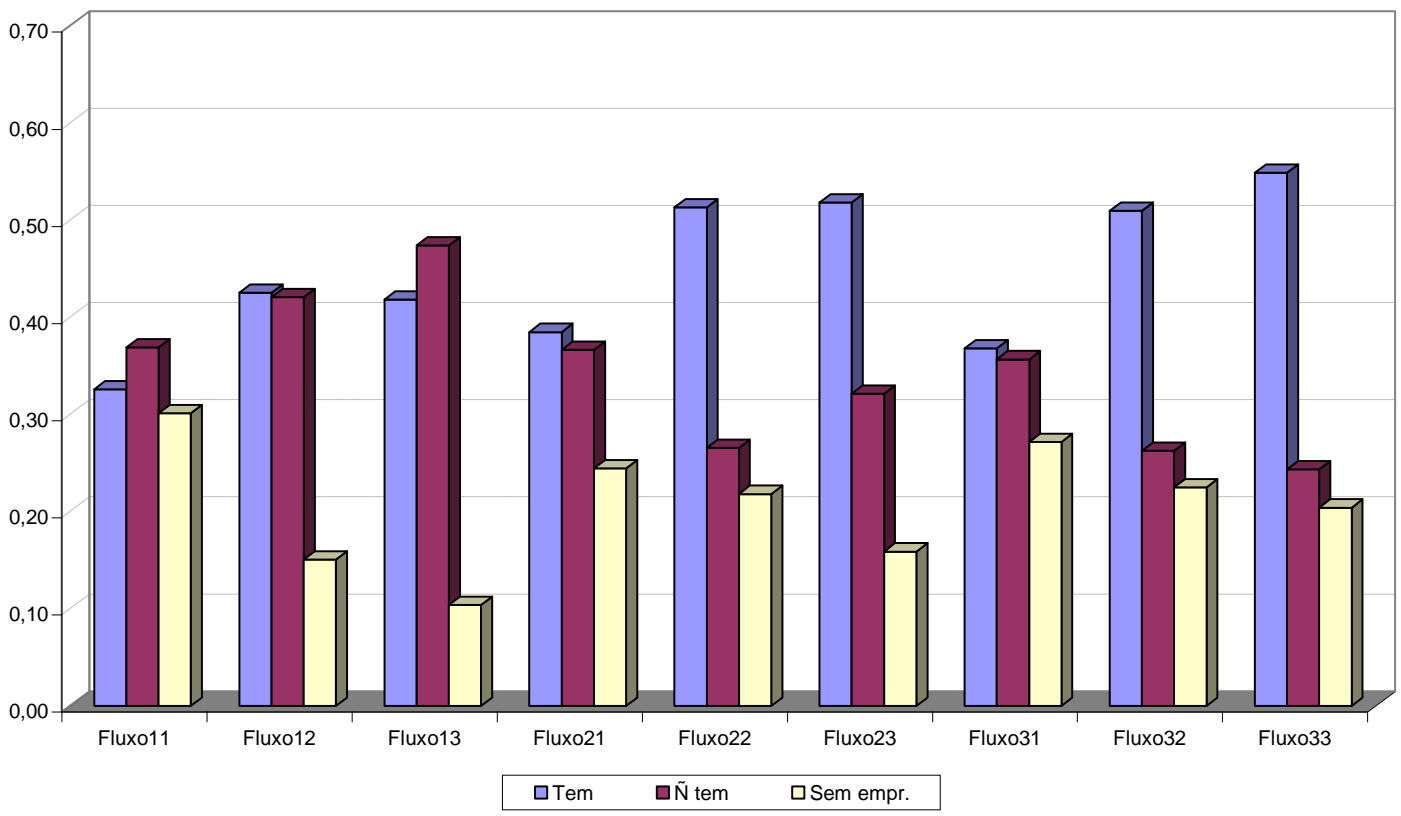

Os grupos de ocupação em que se inserem os migrantes, por fluxo migratório, podem ser visualizados nas Figuras 7 e 8, para os sexos masculino e feminino, respectivamente. De uma forma geral, para os migrantes do sexo masculino, o mercado que mais emprega migrante é o setor de construção civil, independentemente do tipo de fluxo migratório realizado, enquanto que para as mulheres é o setor de serviços. No entanto, deve-se destacar que em direção às cidades menores, além da construção civil, no caso dos homens e, além dos serviços, no caso feminino, o setor que mais emprega é o setor agropecuário e, considerando-se a migração em direção às cidades de grande porte, vêm as atividades administrativas. 


\section{FIGURA 7}

GRUPO DE OCUPAÇÃO, SEXO MASCULINO - BRASIL, 1991

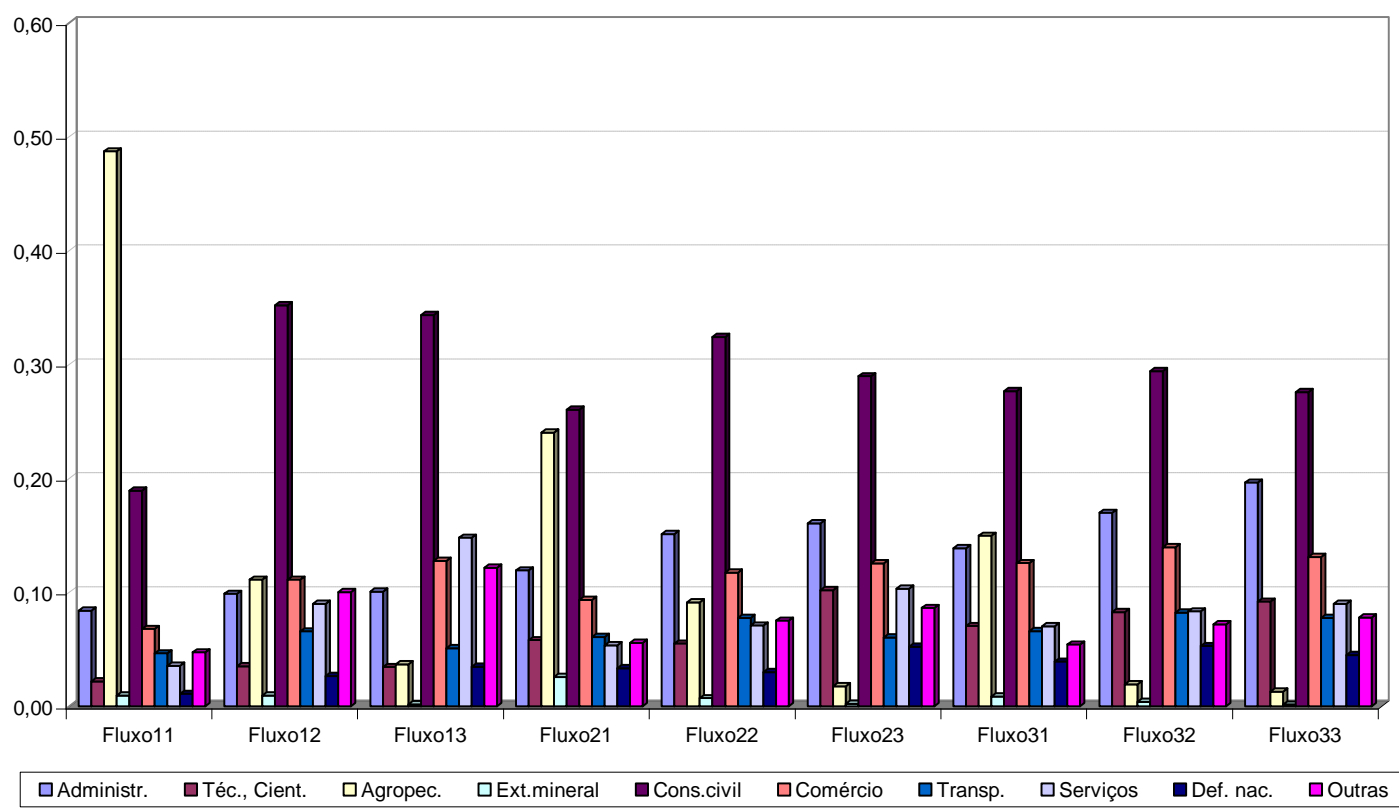

FIGURA 8

GRUPO DE OCUPAÇÃO, SEXO FEMININO - BRASIL, 1991

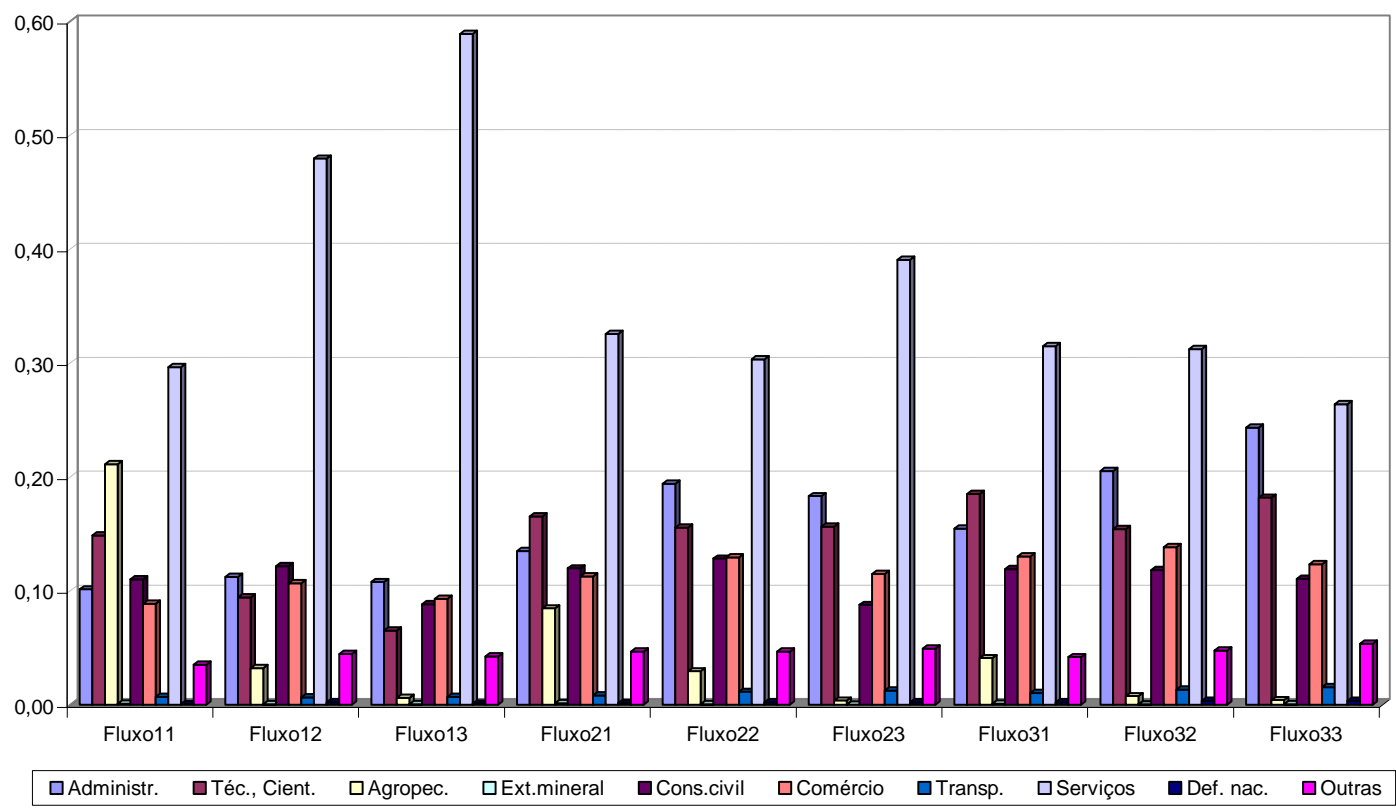


Com relação à renda mensal em salários mínimos, o Fluxo 11, ou seja, para aqueles que ou migraram ou permaneceram em cidades de pequeno porte, há uma maior concentração, em ambos os sexos, em faixas de renda mais baixa. Entre os sexos evidencia-se um diferencial de renda, sendo mais desfavorável para as mulheres, isto pode ser constatado na Figura 9. Esta Figura também revela maiores oportunidades de renda para as pessoas que vivem ou já viveram em grandes cidades. Mas é uma questão de melhores oportunidades ou pelo fato de que estas pessoas estão melhor qualificadas para exercerem cargos com remuneração mais alta?

FIGURA 9

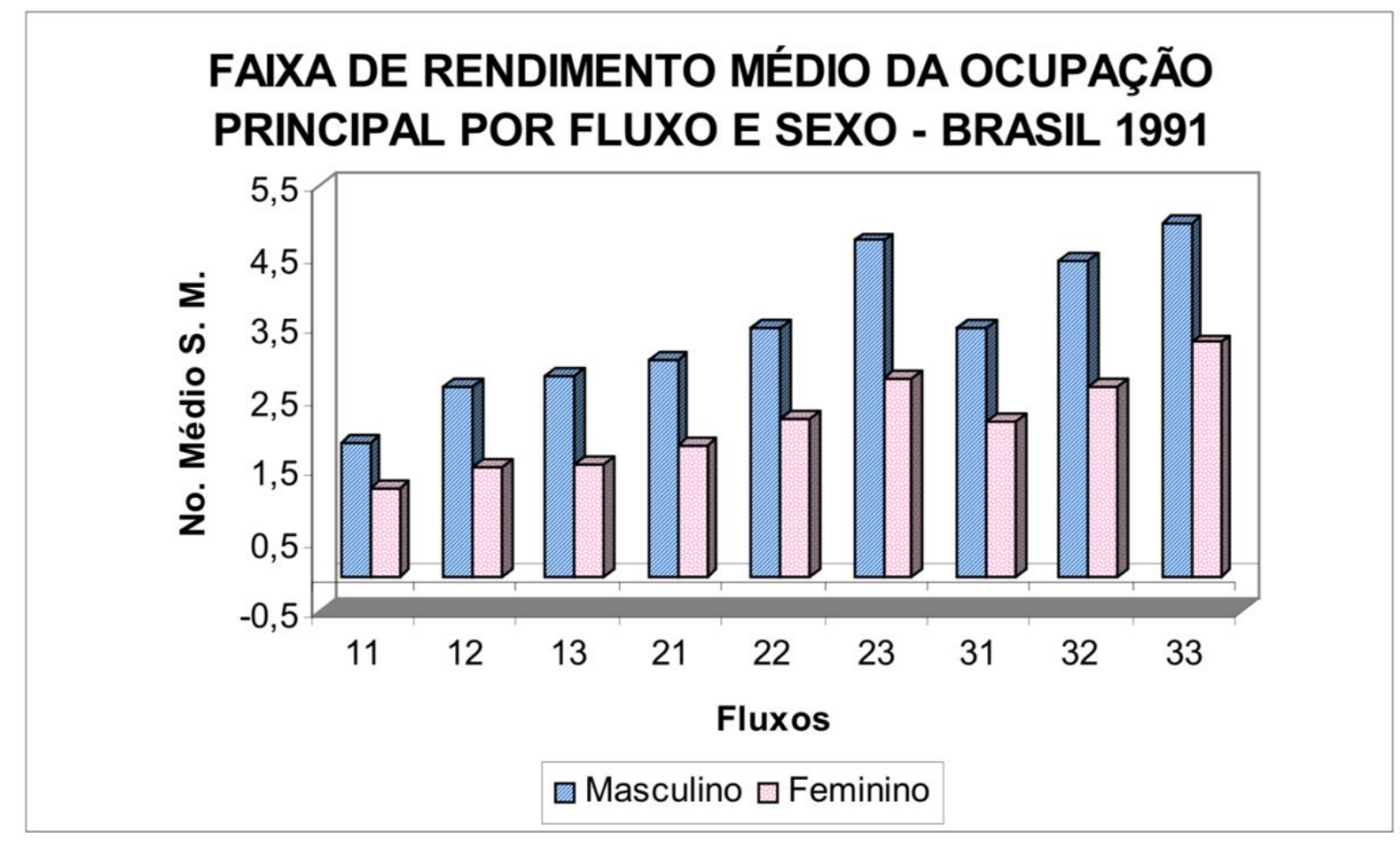


Para o grupo de pessoas que declararam não ter trabalhado nos últimos 12 meses, as condições de atividades podem ser bem ilustradas através de uma figura chamada "Chernoff Face", sugerida por CHERNOFF (1973), para representar um número (n) muito grande de variáveis em forma de rostos bidimensionais, cujas características são determinadas por cada uma das medidas das $\mathrm{n}$ variáveis. A figura é, então, construída designando para cada uma das variáveis uma característica facial e, a partir da padronização das medidas, é feita a composição gráfica, resultando em uma forma de visualização bastante elucidativa do conjunto. A Figura 10 apresenta as características dos migrantes por fluxos migratórios quanto às condições de atividade no Censo de 1991.

Acompanhando as faces no sentido do Fluxo 11 para o Fluxo 13, constata-se o crescente interesse dos migrantes na procura por emprego (características do nariz) nos maiores centros, tendo ou não trabalhado anteriormente, isto se verifica tanto para homens quanto para as mulheres.

Para o sexo feminino, verifica-se que, nas grandes cidades, os percentuais de afazeres domésticos (comprimento da boca) são mais reduzidos que nos demais fluxos, mostrando que, de uma certa forma, as mulheres nas maiores cidades exercem alguma atividade.

Torna-se bastante perceptível o contraste entre o Fluxo11 (face triste) e o Fluxo31 (face alegre). No Fluxo 11 (pequeno para pequeno porte), em termos relativos, possui maior concentração de pessoas sem ocupação (tamanho das orelhas), de doentes ou inválidos (característica da sobrancelha) e atividades de afazeres domésticos (comprimento da boca), para ambos os sexos. Em contrapartida, o Fluxo 31 apresenta uma "face mais tranqüila", ou seja, caracteriza-se por ter menos desocupados (tamanho da orelha) e maior concentração de pessoas que vivem de rendas (concavidade da boca) e menos doentes ou inválidos. Esta situação dos migrantes que saem das cidades de grande porte em direção às cidades de pequeno porte pode estar incluindo os migrantes de retorno, pessoas que já atingiram uma vida financeira estável e retornam para suas cidades de origem a fim de buscarem melhorias na qualidade de vida no sentido de uma vida mais tranqüila, sem a agitação dos grandes centros. Percebe-se a migração de estudantes nos fluxos 31 e 32, o que pode ser explicado pela migração de retorno em que os filhos acompanham seus pais. Para a migração com destino às cidades de portes maiores ao de origem, a presença de estudantes não é muito expressiva. 
FIGURA 10

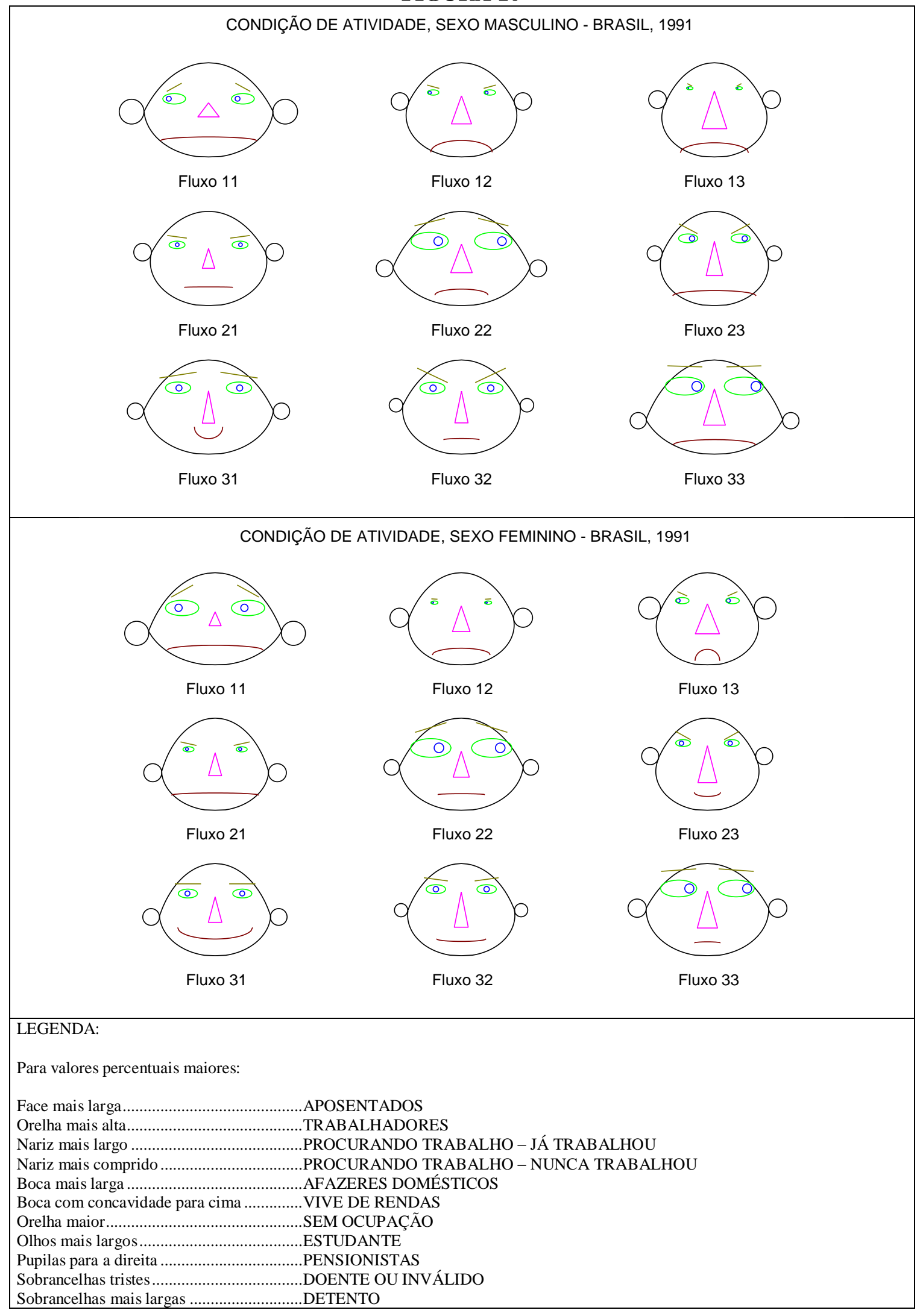


A avaliação do grau de instrução dos migrantes por fluxos revela outro fato interessante, similar entre os sexos (Figuras 11 e 12). Enfocando sobre os migrantes com origem em cidades de baixo porte e que se destinam a maiores centros, verifica-se que ou existe uma propensão maior a concluir o primeiro grau ou a medida que aumenta o porte da cidade a migração torna-se seletiva tendendo a receber apenas aqueles migrantes com melhor nível de instrução. Seja qual for a resposta a esta questão, é fato que os migrantes que se destinam às cidades de grande porte apresentam maior nível educacional. Outro fato que pode ser destacado das Figuras 11 e 12 é que os migrantes cujo fluxo é de média para grandes cidades apresentam maior percentual de pessoas com formação universitária.

\section{FIGURA 11}

\section{GRAU DE INSTRUÇÃO, SEXO MASCULINO - BRASIL, 1991}

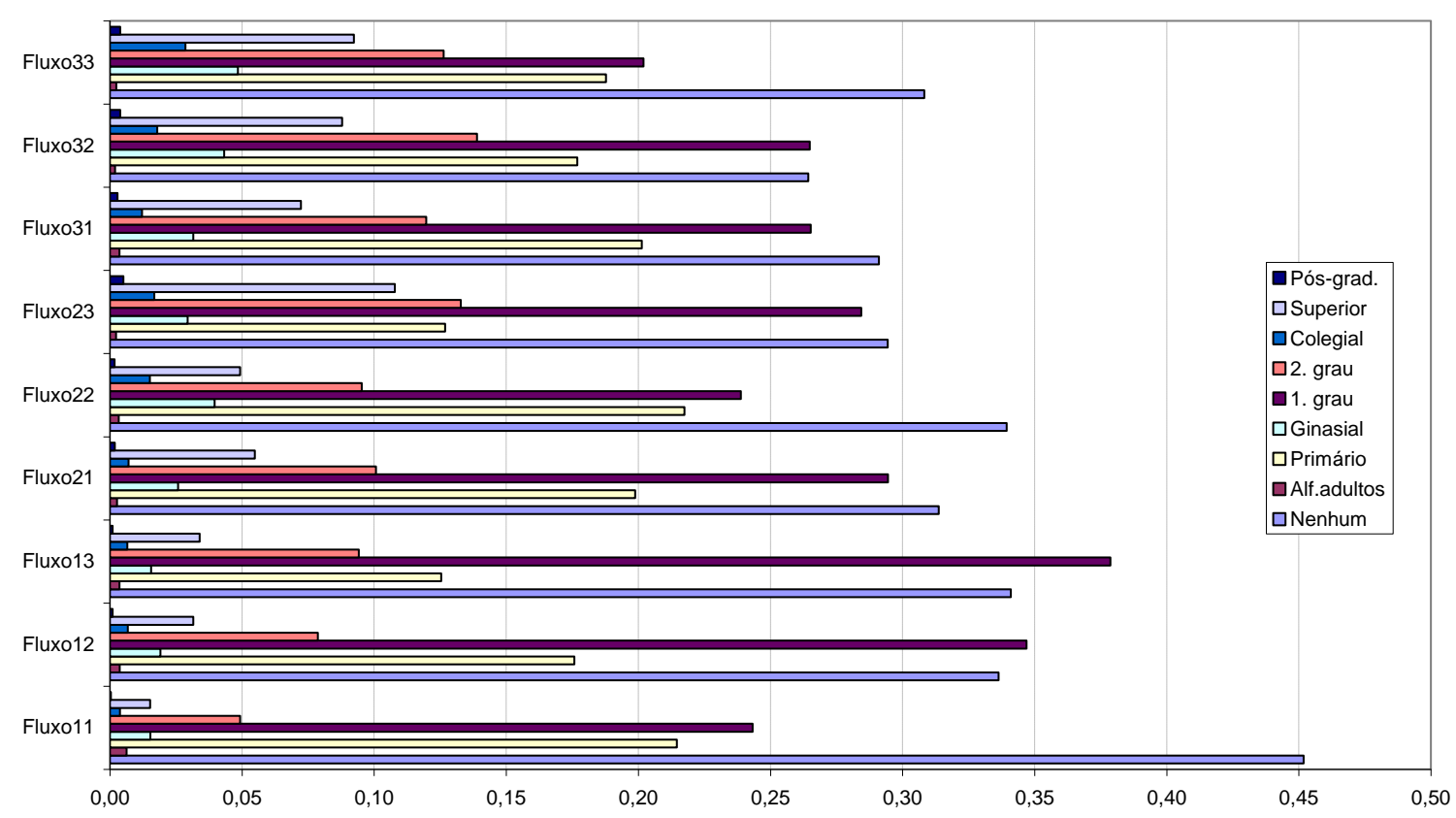


FIGURA 12

GRAU DE INSTRUÇÃO, SEXO FEMININO - BRASIL, 1991

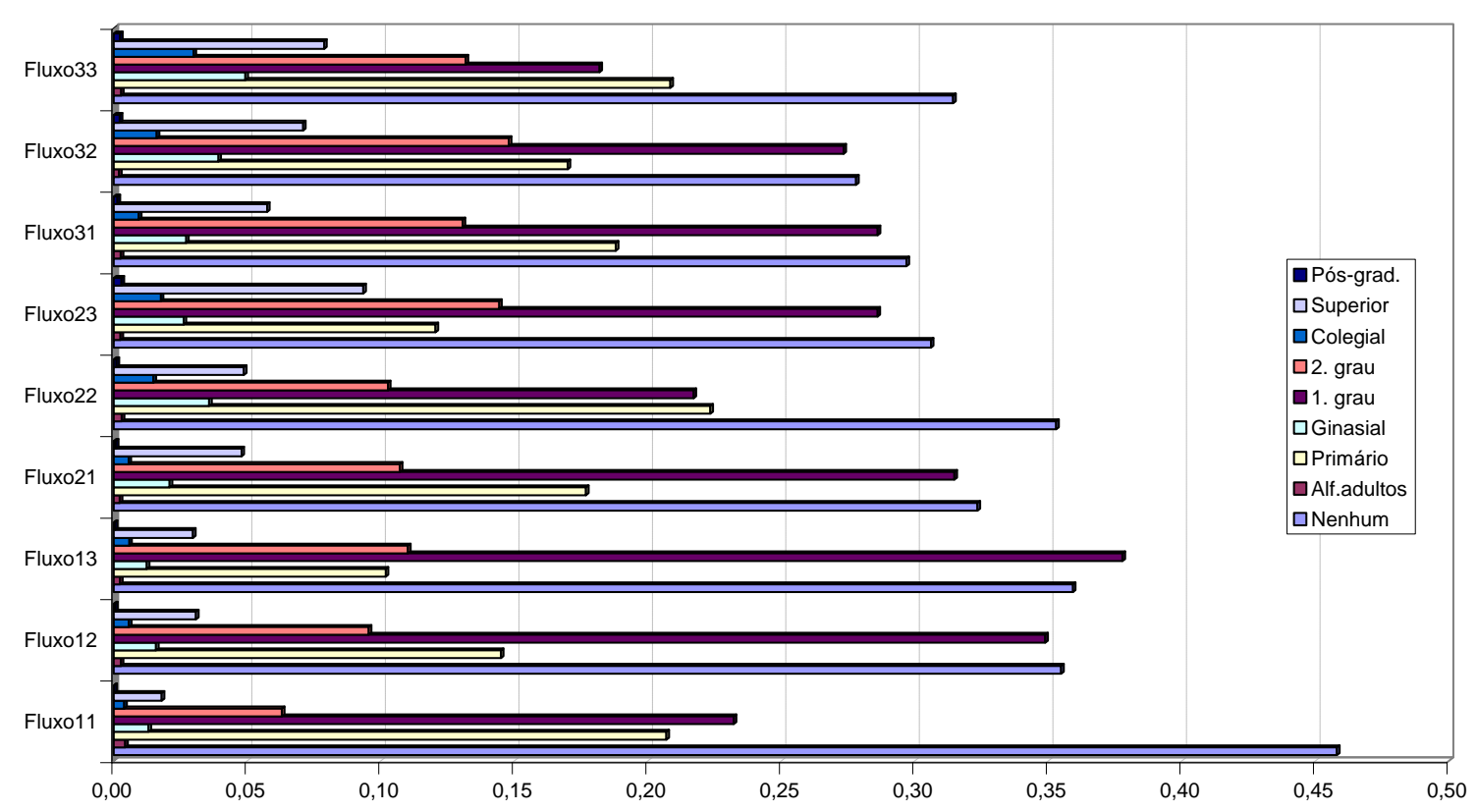

Analisando a escolaridade dos migrantes a partir da variável "Anos de estudo", elaborada pelo IBGE, observa-se que as pessoas do Fluxo 11 apresentam a maior porcentagem de sua população com nenhum ano de estudo, sendo 28,56\% para homens e 26,87\% para mulheres (Figuras 13 e 14, respectivamente). Os migrantes com origem em cidades de pequeno porte e que se destinam a maiores centros apresentam uma elevação no percentual dos grupos com 4 anos e 5 a 7 anos de estudo, os quais podem ser considerados como as pessoas que terminam a primeira fase do ensino fundamental. $\mathrm{O}$ mesmo ocorre com os grupos de migrantes com 8 anos e 9 a 10 anos de estudo, que corresponderiam aos que concluíram o ensino fundamental. Além disso, constata-se que os migrantes com origem em cidades de médio e grande porte apresentam maior percentual em grupos com mais anos de estudo. Isso é comprovado com os Fluxos 23, 32 e 33 que apresentam os maiores percentuais de pessoas com 11 anos e 12 a 14 anos de estudo, que podem ser considerados como aqueles que concluíram o segundo grau.

Percebe-se ainda que os migrantes de cidades de médio porte para grande porte apresentam os maiores percentuais dos grupos de 15 a 16 anos e 17 anos ou mais de estudo, evidenciando um maior percentual de pessoas com formação universitária. $\mathrm{O}$ fato das cidades de maior porte apresentarem os maiores índices de escolaridade pode ser explicado por uma possível seletividade da migração, tendendo a receber apenas aqueles migrantes com melhor nível educacional. 


\section{FIGURA 13}

ANOS DE ESTUDO, SEXO MASCULINO - BRASIL, 1991 (\%)

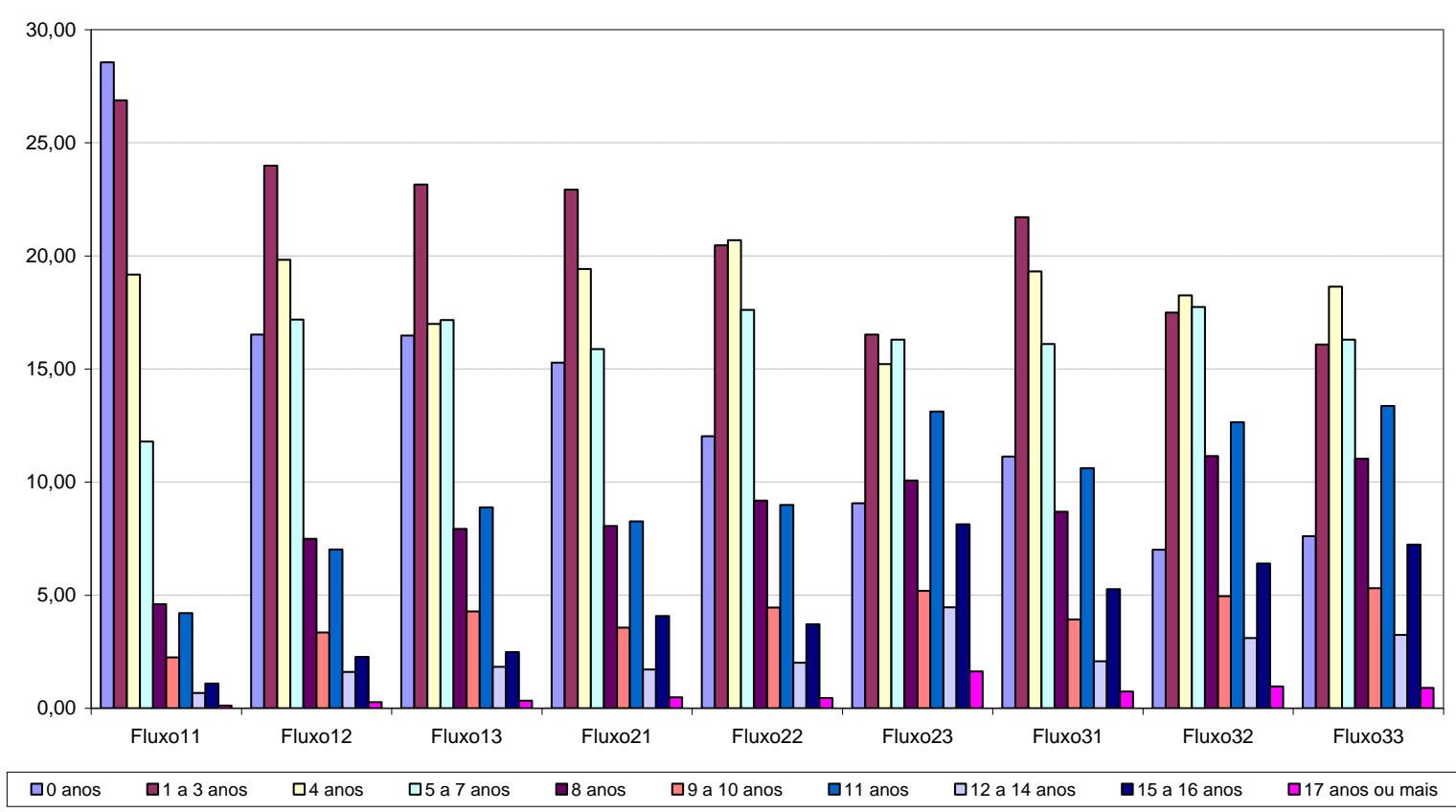

FIGURA 14

ANOS DE ESTUDO, SEXO FEMININO - BRASIL, 1991 (\%)

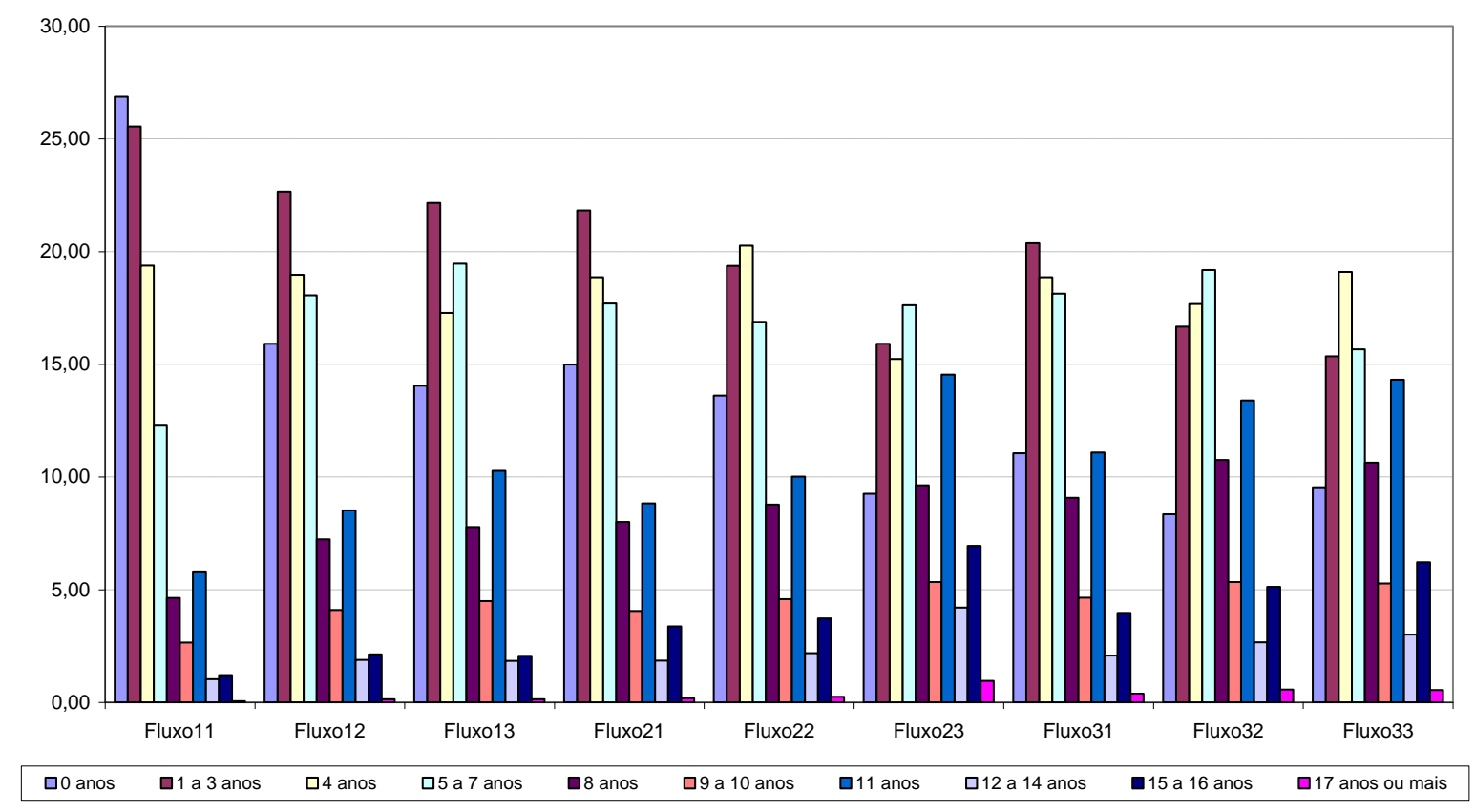




\subsection{Análise multirregional}

A análise multirregional possibilitou o cálculo das esperanças de vida dos migrantes por fluxo migratório apresentadas nas Tabelas 2 e 3, para os sexos masculino e feminino, respectivamente. Estas esperanças de vida refletem o tempo médio de permanência em anos de uma pessoa em cidades de pequeno, médio e grande porte, dependendo de sua origem e destino. Por exemplo, percebe-se que um homem cujo local de residência em 1986 era em cidades de pequeno porte, dos 66,8 anos correspondentes à esperança de vida, passa em média 51,82 anos em cidades de pequeno porte, 8,84 anos em cidades de porte médio e 6,14 anos em cidades de grande porte.

É importante ressaltar ainda que as esperanças de vida total dos diferentes grupos de cidades são semelhantes entre si, considerando-se cada sexo. Desse modo, a esperança de vida total masculina é de 66,8 anos e a feminina é de 76,11 anos, não importando o grupo de cidades que se tome como origem. Isso se deve ao fato de que foram utilizadas as mesmas Taxas Específicas de Mortalidade (TEMs) brasileiras, para cada um dos grupos de municípios. Esse procedimento foi adotado pois, como abordado no terceiro capítulo, o cálculo das TEMs considerando a experiência de morte de cada grupo de cidades, seja através de dados do SIM-DATASUS, seja através do Censo, seria um trabalho muito complexo. 
TABELA 2

ESPERANÇAS DE VIDA

\begin{tabular}{|c|c|c|c|c|c|c|c|c|c|}
\hline Grupo etário & $\begin{array}{l}\text { undo fluxc } \\
\text { Fluxo } 11\end{array}$ & Fluxo 12 & Fluxo 13 & Fluxo 21 & Fluxo 22 & Fluxo 23 & Fluxo 31 & Fluxo 32 & Fluxo 33 \\
\hline 0 & 51,82 & 8,84 & 6,14 & 14,00 & 46,98 & 5,83 & 13,28 & 10,82 & 42,71 \\
\hline 5 & 50,41 & 8,89 & 6,25 & 13,87 & 45,82 & 5,85 & 13,09 & 10,71 & 41,74 \\
\hline 10 & 46,86 & 8,05 & 5,80 & 12,27 & 43,16 & 5,28 & 11,46 & 9,43 & 39,83 \\
\hline 15 & 43,54 & 7,19 & 5,16 & 10,99 & 40,21 & 4,69 & 10,21 & 8,43 & 37,25 \\
\hline 20 & 41,30 & 6,03 & 4,01 & 9,72 & 37,75 & 3,88 & 9,09 & 7,52 & 34,73 \\
\hline 25 & 39,52 & 4,72 & 2,80 & 8,16 & 35,89 & 2,99 & 7,75 & 6,40 & 32,88 \\
\hline 30 & 37,15 & 3,62 & 2,01 & 6,50 & 34,02 & 2,26 & 6,27 & 5,11 & 31,39 \\
\hline 35 & 34,38 & 2,77 & 1,49 & 5,06 & 31,86 & 1,71 & 4,93 & 3,90 & 29,80 \\
\hline 40 & 31,36 & 2,10 & 1,11 & 3,93 & 29,37 & 1,27 & 3,85 & 2,92 & 27,80 \\
\hline 45 & 28,19 & 1,59 & 0,83 & 3,07 & 26,60 & 0,94 & 3,03 & 2,22 & 25,37 \\
\hline 50 & 25,03 & 1,20 & 0,62 & 2,41 & 23,73 & 0,71 & 2,42 & 1,71 & 22,72 \\
\hline 55 & 22,01 & 0,90 & 0,47 & 1,90 & 20,91 & 0,57 & 1,94 & 1,34 & 20,10 \\
\hline 60 & 19,35 & 0,70 & 0,37 & 1,52 & 18,42 & 0,47 & 1,57 & 1,08 & 17,76 \\
\hline 65 & 17,01 & 0,57 & 0,31 & 1,24 & 16,23 & 0,42 & 1,28 & 0,89 & 15,72 \\
\hline 70 & 15,19 & 0,50 & 0,28 & 1,07 & 14,51 & 0,39 & 1,10 & 0,77 & 14,10 \\
\hline 75 & 14,47 & 0,49 & 0,27 & 1,04 & 13,81 & 0,38 & 1,06 & 0,74 & 13,44 \\
\hline $80+$ & 15,89 & 0,53 & 0,30 & 1,16 & 15,13 & 0,42 & 1,22 & 0,85 & 14,65 \\
\hline
\end{tabular}

TABELA 3

ESPERANÇAS DE VIDA

segundo fluxo entre cidades brasileiras de diferentes portes, sexo feminino - Censo 1991

\begin{tabular}{c|ccccccccc} 
Grupo etário & Fluxo 11 & Fluxo 12 & Fluxo 13 & Fluxo 21 & Fluxo 22 & Fluxo 23 & Fluxo 31 & Fluxo 32 & Fluxo 33 \\
\hline 0 & 55,63 & 11,50 & 8,98 & 15,66 & 52,60 & 7,85 & 14,75 & 13,00 & 48,36 \\
5 & 53,67 & 11,49 & 9,08 & 15,36 & 51,06 & 7,82 & 14,39 & 12,76 & 47,08 \\
10 & 50,40 & 10,51 & 8,45 & 13,67 & 48,57 & 7,12 & 12,67 & 11,34 & 45,36 \\
15 & 47,98 & 9,27 & 7,25 & 12,19 & 46,06 & 6,25 & 11,23 & 10,10 & 43,17 \\
20 & 46,67 & 7,58 & 5,45 & 10,54 & 44,07 & 5,09 & 9,75 & 8,83 & 41,13 \\
25 & 45,24 & 5,87 & 3,85 & 8,59 & 42,46 & 3,90 & 8,06 & 7,33 & 39,56 \\
30 & 42,89 & 4,53 & 2,83 & 6,73 & 40,57 & 2,96 & 6,39 & 5,79 & 38,07 \\
35 & 39,89 & 3,53 & 2,19 & 5,23 & 38,10 & 2,28 & 4,98 & 4,46 & 36,16 \\
40 & 36,59 & 2,76 & 1,74 & 4,13 & 35,16 & 1,79 & 3,94 & 3,48 & 33,66 \\
45 & 33,15 & 2,17 & 1,38 & 3,32 & 31,94 & 1,44 & 3,19 & 2,77 & 30,74 \\
50 & 29,66 & 1,74 & 1,11 & 2,70 & 28,62 & 1,18 & 2,59 & 2,24 & 27,67 \\
55 & 26,28 & 1,41 & 0,89 & 2,19 & 25,42 & 0,97 & 2,09 & 1,84 & 24,64 \\
60 & 23,10 & 1,14 & 0,73 & 1,79 & 22,35 & 0,82 & 1,69 & 1,52 & 21,77 \\
65 & 20,24 & 0,95 & 0,63 & 1,50 & 19,59 & 0,72 & 1,37 & 1,26 & 19,18 \\
70 & 17,83 & 0,84 & 0,56 & 1,31 & 17,29 & 0,64 & 1,16 & 1,09 & 16,99 \\
75 & 16,47 & 0,79 & 0,54 & 1,23 & 15,97 & 0,59 & 1,07 & 1,00 & 15,72 \\
$80+$ & 17,09 & 0,83 & 0,56 & 1,29 & 16,57 & 0,62 & 1,11 & 1,07 & 16,30 \\
\hline
\end{tabular}

Obs.: Os fluxos se referem ao movimento entre cidades pequenas (1), médias (2) e grandes (3), entre 01/09/1986 e 01/09/1991.

Fonte: Censo Demográfico 1991, IBGE. 
A Figura 15 ilustra o tempo médio esperado em anos gastos por uma pessoa, ao longo de sua vida, nos três tipos de classificação das cidades. Para o sexo masculino, percebe-se que há uma maior tendência de permanência em cidades de mesmo porte para os municípios pequenos, com um total de 51,82 anos. Quanto às cidades grandes, estas apresentam o maior tempo médio esperado de vida em municípios de diferentes portes, sendo 13,28 anos em cidades pequenas e 10,82 anos em cidades médias. Para o sexo feminino, a tendência é a mesma, com indivíduos de origem em cidades pequenas tendendo a viver nesses tipos de municípios um período de 55,63 anos. E considerando as grandes cidades como origem, 14,75 anos são vividos em municípios pequenos e 13,00 anos em municípios médios.

FIGURA 15

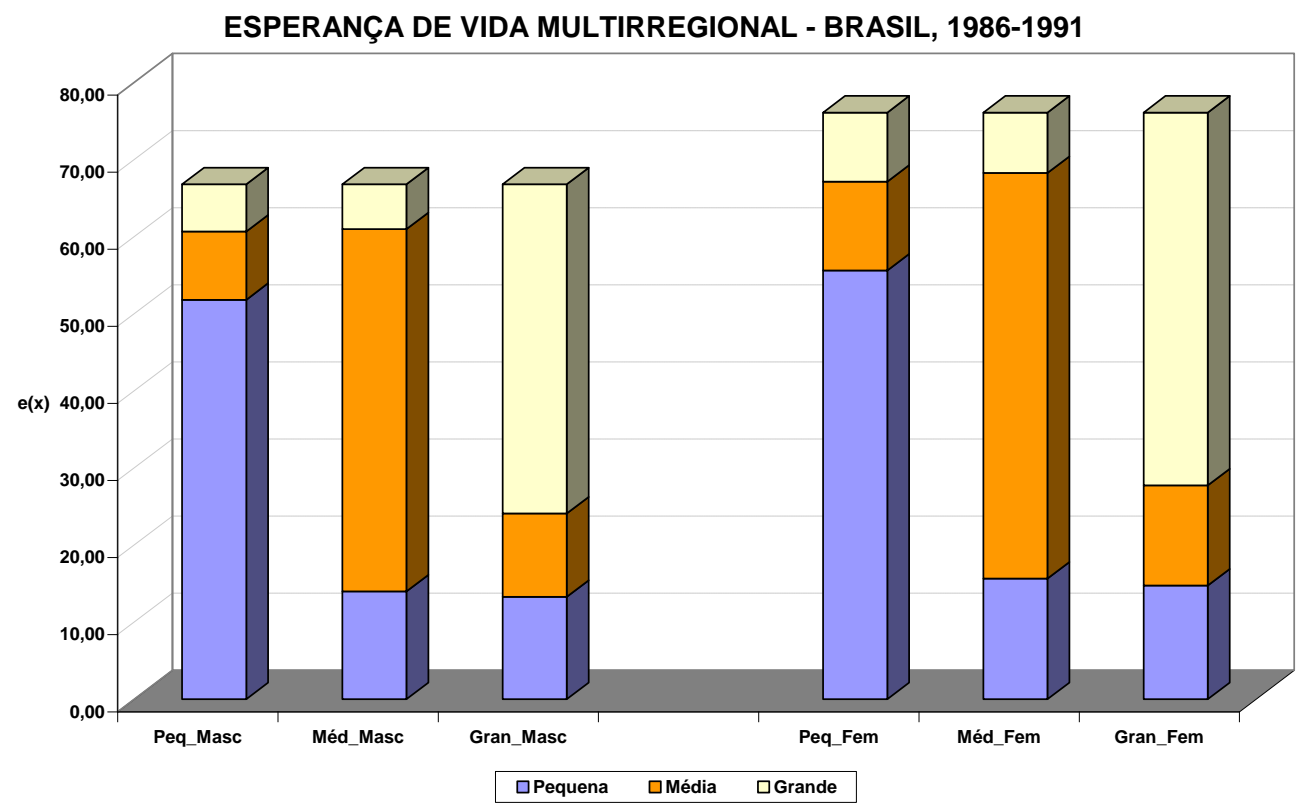


As Figuras 16 e 17 permitem a visualização das esperanças de vida por grupo etário, para os sexos masculino e feminino.

\section{FIGURA 16}

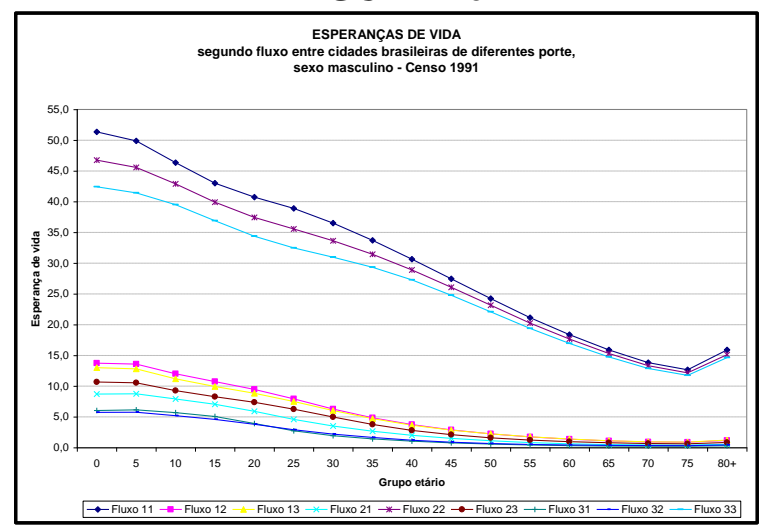

FIGURA 17

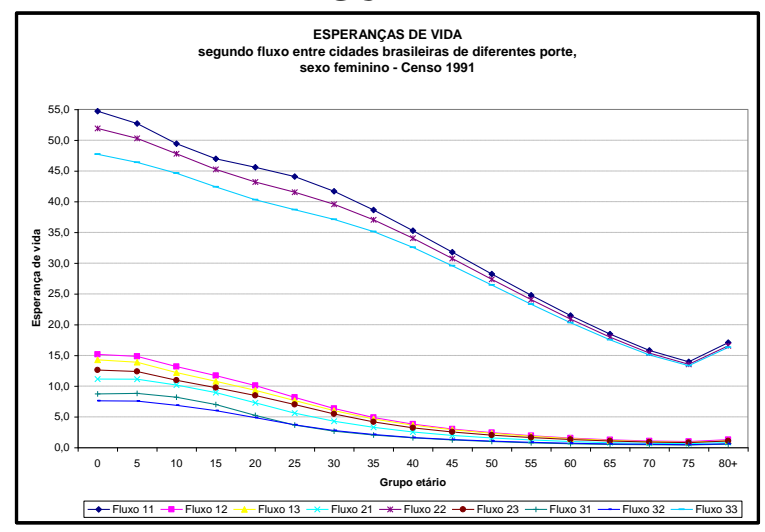

Com base no método de tabelas de sobrevivência multirregional, foram calculadas as razões de sobrevivência para os nove fluxos em estudo apresentadas nas Tabelas 4 e 5 para os sexos masculino e feminino, respectivamente.

\section{TABELA 4}

RAZÕES DE SOBREVIVÊNCIA

segundo fluxos entre cidades brasileiras de diferentes portes, sexo masculino - Censo 1991

\begin{tabular}{|c|c|c|c|c|c|c|c|c|c|}
\hline Grupo etário & Fluxo 11 & Fluxo 12 & Fluxo 13 & Fluxo 21 & Fluxo 22 & Fluxo 23 & Fluxo 31 & Fluxo 32 & Fluxo 33 \\
\hline 0 & 0,9443 & 0,0165 & 0,0096 & 0,0334 & 0,9259 & 0,0112 & 0,0325 & 0,0284 & 0,9095 \\
\hline 5 & 0,9578 & 0,0233 & 0,0161 & 0,0411 & 0,9400 & 0,0161 & 0,0391 & 0,0347 & 0,9234 \\
\hline 10 & 0,9381 & 0,0288 & 0,0273 & 0,0387 & 0,9346 & 0,0210 & 0,0341 & 0,0312 & 0,9289 \\
\hline 15 & 0,9159 & 0,0362 & 0,0367 & 0,0446 & 0,9172 & 0,0269 & 0,0376 & 0,0353 & 0,9159 \\
\hline 20 & 0,9162 & 0,0366 & 0,0320 & 0,0517 & 0,9064 & 0,0267 & 0,0445 & 0,0426 & 0,8976 \\
\hline 25 & 0,9284 & 0,0312 & 0,0218 & 0,0513 & 0,9081 & 0,0220 & 0,0462 & 0,0451 & 0,8901 \\
\hline 30 & 0,9351 & 0,0261 & 0,0158 & 0,0451 & 0,9138 & 0,0181 & 0,0423 & 0,0410 & 0,8937 \\
\hline 35 & 0,9371 & 0,0221 & 0,0125 & 0,0381 & 0,9185 & 0,0151 & 0,0362 & 0,0337 & 0,9018 \\
\hline 40 & 0,9340 & 0,0188 & 0,0104 & 0,0325 & 0,9186 & 0,0121 & 0,0306 & 0,0271 & 0,9056 \\
\hline 45 & 0,9245 & 0,0163 & 0,0088 & 0,0289 & 0,9112 & 0,0095 & 0,0273 & 0,0226 & 0,8997 \\
\hline 50 & 0,9051 & 0,0141 & 0,0073 & 0,0262 & 0,8928 & 0,0076 & 0,0256 & 0,0194 & 0,8815 \\
\hline 55 & 0,8778 & 0,0118 & 0,0060 & 0,0243 & 0,8649 & 0,0064 & 0,0246 & 0,0176 & 0,8534 \\
\hline 60 & 0,8425 & 0,0099 & 0,0050 & 0,0221 & 0,8294 & 0,0060 & 0,0230 & 0,0164 & 0,8181 \\
\hline 65 & 0,7867 & 0,0086 & 0,0044 & 0,0189 & 0,7747 & 0,0062 & 0,0201 & 0,0145 & 0,7652 \\
\hline 70 & 0,7057 & 0,0078 & 0,0043 & 0,0162 & 0,6953 & 0,0062 & 0,0164 & 0,0120 & 0,6893 \\
\hline 75 & 2,5061 & 0,1022 & 0,0569 & 0,2196 & 2,3653 & 0,0804 & 0,2260 & 0,1576 & 2,2817 \\
\hline
\end{tabular}

Obs.: Os fluxos se referem ao movimento entre as cidades pequenas (1), médias (2) e grandes (3), entre 01/09/1986 e 01/09/1991. 


\section{TABELA 5}

RAZÕES DE SOBREVIVÊNCIA

\begin{tabular}{|c|c|c|c|c|c|c|c|c|c|}
\hline Grupo etário & Fluxo 11 & Fluxo 12 & Fluxo 13 & Fluxo 21 & Fluxo 22 & Fluxo 23 & Fluxo 31 & Fluxo 32 & Fluxo 33 \\
\hline 0 & \begin{tabular}{|l|}
0,9488 \\
\end{tabular} & 0,0176 & 0,0120 & 0,0332 & 0,9334 & 0,0118 & 0,0321 & 0,0280 & 0,9182 \\
\hline 5 & 0,9457 & 0,0277 & 0,0247 & 0,0417 & 0,9375 & 0,0189 & 0,0393 & 0,0355 & 0,9234 \\
\hline 10 & 0,9208 & 0,0366 & 0,0400 & 0,0416 & 0,9300 & 0,0258 & 0,0368 & 0,0345 & 0,9261 \\
\hline 15 & 0,9085 & 0,0425 & 0,0451 & 0,0477 & 0,9178 & 0,0307 & 0,0402 & 0,0388 & 0,9171 \\
\hline 20 & 0,9210 & 0,0390 & 0,0350 & 0,0507 & 0,9157 & 0,0286 & 0,0433 & 0,0430 & 0,9087 \\
\hline 25 & 0,9395 & 0,0312 & 0,0227 & 0,0458 & 0,9252 & 0,0224 & 0,0411 & 0,0413 & 0,9111 \\
\hline 30 & 0,9500 & 0,0251 & 0,0158 & 0,0374 & 0,9364 & 0,0171 & 0,0347 & 0,0348 & 0,9214 \\
\hline 35 & 0,9531 & 0,0209 & 0,0128 & 0,0299 & 0,9435 & 0,0133 & 0,0277 & 0,0275 & 0,9315 \\
\hline 40 & 0,9521 & 0,0174 & 0,0111 & 0,0250 & 0,9448 & 0,0109 & 0,0234 & 0,0223 & 0,9349 \\
\hline 45 & 0,9465 & 0,0150 & 0,0098 & 0,0225 & 0,9390 & 0,0097 & 0,0217 & 0,0193 & 0,9303 \\
\hline 50 & 0,9349 & 0,0139 & 0,0087 & 0,0212 & 0,9276 & 0,0087 & 0,0207 & 0,0179 & 0,9189 \\
\hline 55 & 0,9165 & 0,0129 & 0,0078 & 0,0199 & 0,9094 & 0,0078 & 0,0198 & 0,0173 & 0,9000 \\
\hline 60 & 0,8888 & 0,0115 & 0,0069 & 0,0184 & 0,8810 & 0,0079 & 0,0185 & 0,0165 & 0,8722 \\
\hline 65 & 0,8414 & 0,0104 & 0,0066 & 0,0169 & 0,8333 & 0,0082 & 0,0164 & 0,0153 & 0,8268 \\
\hline 70 & 0,7646 & 0,0099 & 0,0068 & 0,0158 & 0,7575 & 0,0080 & 0,0143 & 0,0135 & 0,7536 \\
\hline 75 & 2,8460 & 0,1613 & 0,1094 & 0,2514 & 2,7443 & 0,1209 & 0,2177 & 0,2068 & 2,6921 \\
\hline
\end{tabular}

\section{Conclusão}

A partir dos dados do Censo Demográfico de 1991, foi possível analisar a estrutura etária dos migrantes de municípios pequenos, médios e grandes e suas características sócio-econômicas. Com isto, pôde-se perceber o perfil dos migrantes entre o período de 01 de setembro de 1986 e 01 de setembro de 1991, quanto ao porte das cidades. Constatou-se que os migrantes com origem ou destino às cidades de maior porte apresentam fecundidade mais reduzida. Ainda com base nos dados das pessoas que permaneceram em municípios grandes, no período analisado, é possível afirmar que o padrão populacional desses indivíduos tende à estabilidade.

Além disso, observa-se um grande fluxo de pessoas residentes em pequenas cidades, em direção a grandes municípios, no grupo etário de 20 a 24 anos. Isto pode estar indicando que estes indivíduos estão se dirigindo aos grandes centros urbanos em busca de emprego, já que entraram há pouco tempo no grupo economicamente ativo da sociedade. Quanto ao fluxo inverso, das pessoas que se dirigem de municípios de maior para menor porte, observa-se que há uma maior concentração em grupos etários mais elevados, a partir dos 25 anos. Aqui pode estar ocorrendo o fluxo conhecido como migração de retorno, em que os indivíduos vindos de pequenos municípios, retornam a estes lugares de nascimento, após viverem um período de tempo em cidades de maior porte.

Quanto à fecundidade dos migrantes dos fluxos migratórios entre as cidades de diferentes portes, observa-se que há uma tendência de crescimento nas taxas quando o destino do migrante é um município de menor porte. Por outro lado, ao se dirigirem a cidades de maior porte, os indivíduos tendem a apresentar menores taxas. 
Analisando ainda os resultados obtidos na elaboração do perfil dos migrantes, pode-se constatar, dentre outros, que as pessoas que se dirigem aos grandes municípios tendem a ser solteiros, possuir carteira de trabalho assinada, apresentar maior renda mensal e revelar maior nível educacional. Esses dados geram uma importante discussão. Por um lado, esses melhores diagnósticos das pessoas que se dirigem aos grandes centros podem ser explicados pelo fato de que esses municípios possuem melhores oportunidades de vida. Por outro lado, pode-se argumentar que, justamente por um melhor nível sócioeconômico já na cidade de origem, o indivíduo tende a deslocar-se aos grandes municípios. Deste modo, esta última afirmação estaria evidenciando que justamente pelo fato de haver uma desigualdade na quantidade e qualidade de empregos entre municípios de diferentes portes, a migração em direção às grandes cidades seria bastante seletiva quanto ao perfil dos imigrantes. Esse fenômeno tende, senão a aumentar, pelo menos a manter as desigualdades existentes entre os municípios brasileiros. Uma forma de reverter ou, pelo menos, diminuir essas diferenças seria a implementação de políticas que propiciassem o crescimento sócio-econômico dos pequenos municípios, formando e atraindo indivíduos com melhores níveis educacionais e maiores patamares de renda.

É importante salientar que os resultados relativos ao perfil sócio-econômico dos migrantes entre cidades de diferentes portes foram obtidos a partir de cruzamentos simples entre variáveis do Censo Demográfico de 1991, como se constatou nas Figuras e Tabelas do capítulo anterior. Uma forma de aprofundar essas análises seria a elaboração de trabalhos que permitissem uma análise estatística desses dados censitários. Para isto, seriam organizados modelos, com um conjunto de variáveis explicativas, capazes de evidenciar a preferência dos migrantes por um determinado grupo de cidades quanto ao porte.

Quanto às técnicas e resultados da demografia multirregional apresentados nos capítulos anteriores, é importante levantar algumas considerações. As tabelas de vida aqui apresentadas consideram a presença de migrações internas em um sistema que possui várias regiões interagindo entre si. Essas dimensões de emigração e imigração captadas entre as regiões em estudo não são captadas por uma análise que tem por objetivo a construção de tabelas de vida unirregionais. Dessa forma, essas técnicas possibilitaram calcular as esperanças de vida e as razões de sobrevivência dos fluxos entre cidades de diferentes portes. Esses dados apresentam a quantidade de anos, em média, que uma pessoa permaneceria em cidades de pequeno, médio e grande porte, levando em consideração seu local de residência.

As constatações observadas, principalmente nas esperanças de vida, são muito interessantes de serem novamente ressaltadas. Constatou-se que, tanto para os homens como para as mulheres, os indivíduos que residiam em municípios pequenos, em 01 de setembro de 1986, tendem a permanecer uma maior quantidade de anos em cidades com este mesmo porte, quando comparados aos dois outros grupos de cidades. E quando se analisam os dados das grandes cidades, observa-se que os indivíduos que residiam nesses municípios tendem a viver um maior tempo de vida em municípios de diferentes portes: 
pequenos ou médios. Este é um resultado muito importante do presente trabalho, já que está sendo evidenciado que as pessoas de grandes municípios tendem a migrar mais que as outras.

Em um primeiro momento, poder-se-ia afirmar que há uma contradição entre os resultados obtidos com o perfil dos migrantes e com as tabelas de vida multirregionais. Porém, não é bem isso o que ocorre. Constatou-se, com os dados descritivos, que o fluxo de pequenos para municípios de maior porte é caracterizado por indivíduos que apresentam maiores níveis sócio-econômicos do que aqueles que se direcionam de grandes para pequenos municípios. E com os dados das tabelas de vida, constatou-se que há uma maior tendência de pessoas de cidades grandes migrarem para outros municípios de diferentes portes. Deste modo, o que se está afirmando é que as grandes cidades possuem ou atraem pessoas com melhores condições de vida, porém os habitantes com origem nestas cidades são as que mais tendem a apresentar um maior número de anos vividos em municípios de outros portes. Isto pode estar evidenciando uma mudança no padrão migratório do Brasil, que antes era caracterizado por um fluxo predominantemente de pequenos para médios ou grandes municípios, e agora está apresentando uma maior tendência no fluxo de maiores para menores cidades. 


\section{Referências bibliográficas}

BAENINGER, R. Redistribución espacial de la población: características y tendencias del caso brasileño. Boletín CELADE, 1998.

CHERNOFF. H. Using faces to represent points in K-dimensional space graphically. Journal of the American Statistical Association, v.68, n.342, p.361-368, 1973.

DINIZ, C.C. A dinâmica regional recente da economia brasileira e suas perspectivas. Texto para discussão - IPEA, Brasília, n.375, Jun./1995.

FÍGOLI, M.G.B.; L.R. WONG; D.O. SAWYER; J.A.M. de CARVALHO ProjeçãoMultirregional da População por Unidades da Federação. In: ANAIS: XII Encontro Nacional de Estudos Populacionais: BRASIL, 500 ANOS: Mudanças e Continuidades. Caxambu, MG, 23 a 27 de outubro de 2000.

INSTITUTO BRASILEIRO DE GEOGRAFIA E ESTATÍSTICA. Censo Demográfico de 1991.

MARTINE, G. A redistribuição espacial da população brasileira durante a década de 80 . Texto para discussão - IPEA, Brasília, n.329, 1994.

PRONEX - Programa de Apoio ao Núcleo de Excelência. Dinâmica Demográfica de Envolvimento Regional e Políticas Públicas. Financiado pelo CNPQ e desenvolvido pelo CEDEPLAR - UFMG.

ROGERS, A. Multiregional Demography: principles, methods and extensions. Chichester: John Wiley \& Sons, 1995. 236p.

SACHS, C. São Paulo: políticas públicas e habitação popular. São Paulo: Editora da Universidade de São Paulo, 1999. 277p. 